\title{
Physiological and Ethological Effects of Caffeine, Theophylline, Cocaine and Atropine; Study Using the Ant Myrmica sabuleti (Hymenoptera, Formicidae) as A Biological Model
}

\author{
Marie-Claire Cammaerts ${ }^{1}$, Zoheir Rachidi ${ }^{1} \&$ Geoffrey Gosset ${ }^{1}$ \\ ${ }^{1}$ Faculté des Sciences, Université Libre de Bruxelles, Bruxelles, Belgium \\ Correspondence: Marie-Claire Cammaerts, DBO, CP 160/12, Université Libre de Bruxelles, 50, Av. F.D. \\ Roosevelt, 1050 Bruxelles, Belgium. E-mail: mtricot@ulb.ac.be
}

Received: April 22, 2014 Accepted: May 22, 2014 Online Published: May 29, 2014

doi:10.5539/ijb.v6n3p64 URL: http://dx.doi.org/10.5539/ijb.v6n3p64

\begin{abstract}
Aiming to check if ants can be used as biological models, we studied the effects of four alkaloids on the ant Myrmica sabuleti. Caffeine and theophylline increased the ants' linear speed, decreased their precision of reaction and their food consumption, did not affect their response to pheromones, nor their audacity, largely increased their conditioning ability and their memory; ants did not become habituated to nor dependent on these alkaloids. The effects of caffeine exponentially decreased in the course of time; those of theophylline slowly decreased sigmoidally after a latency period. Cocaine decreased the ants' linear speed, their precision of reaction, their response to pheromones and their consumption of food; it increased their audacity; under its consumption, ants became unable to acquire conditioning. Ants became habituated to and dependent on such an alkaloid. The effects of cocaine rapidly vanished in the course of time. Atropine did not affect the ants' locomotion, decreased their precision of reaction and their response to pheromones because it reduced their olfactory perception; it did not affect their audacity, decreased their food consumption, increased the speed in acquiring conditioning but not the quality of the resulting conditioning; it slightly increased their memory. Ants did not become habituated to, nor dependent on this alkaloid. The effects of atropine vanished in about $20 \mathrm{hrs}-30 \mathrm{hrs}$. These effects are in agreement with those known by physiologists, psychologists and doctors in medicine; observations made on ants even lead to more precise deductions. Consequently, ants can efficiently be used as biological models.
\end{abstract}

Keywords: conditioning, dependence, habituation, locomotion, memory

\section{Introduction}

Animals can be used as biological models, for studying several physiological functions, because most of the biological processes are similar for all animals, also for human beings (i.e. genetics, metabolism, nervous cells functioning). Invertebrates are more and more used as biological models because they offer scientists many advantages, among others a short life cycle and a simple anatomy, being available in large numbers, presenting few ethical problems (Sovik \& Barron, 2013; Wolf \& Heberlein, 2003). Some invertebrates are become famous as biological models, for instance, Dendrocelium lacteum, Caenorhabdotes elegans, Aplysia californica, Tribolim castaneum, Drosophila melanogaster, Apis mellifera (Kolb \& Wishaw, 2002; Wehner \& Gehring, 1999; Deutsch, 1994; Devineni \& Heberlein, 2013). Among the invertebrates, insects, and especially social hymenoptera, are advantageously used as biological models (Andre, Wirtz, \& Das, 1989; Doring \& Chittka, 2011). Bees, for instance, are often used as biological models (for instance, Abramson, Wells, \& Janko, 2007). Thousands of ants can easily be maintained in laboratories, at low cost and very conveniently, throughout the entire year. Despite being invertebrates, ants are among the most evolved organisms as for their morphology, their physiology, their social organization and their behavior. They are the most morphologically elaborate hymenoptera, having indeed a unique resting position of their labium, mandibles and maxilla (Keller, 2011a, 2011b), as well as a lot of glands emitting numerous, efficient compounds (Billen \& Morgan, 1998). Their societies are highly organized with a strong division of labor, an age-based polyethism and social regulation (Hölldobler \& Wilson, 1990). Their behavior is incomparable: they care for their brood, build sophisticated nests, chemically mark the inside of their nest, and, differently, their nest entrances, their nest surroundings and their foraging area (Passera \& Aron, 2005). They generally use an alarm signal, a trail pheromone, and a recruitment signal (Passera \& Aron, 2005); they are able to navigate using memorized visual and olfactory cues (cf. Cammaerts, 2012a, 2012b, and references therein); 
they efficiently recruit nestmates where, when and as long as it is necessary (Passera, 2006), and, finally, they provide their area with cemeteries (Keller \& Gordon, 2006). Mankind has probably not yet discovered all the ants' capabilities. The biology of some ant species is now very well known: for instance Solenopsis invicta, Cataglyphis cursor, Atta sexdens, and Gigantiops destructor (Passera \& Aron, 2005).

We have largely studied species of the genus Myrmica, and above all Myrmica sabuleti Meinert 1861 (Cammaerts, 2004, 2008; Cammaerts \& Rachidi, 2009). We became aware that M. sabuleti may be a good biological model after studies concerning the impact of age, activity and diet on the ants' conditioning capability (Cammaerts \& Gosset, 2014). At that time, we presumed that several other factors may also impact the ants' (and any animals') learning as well as other ethological and physiological functions. Among these factors, some drugs may influence memorization (this has been observed in bees: Chittka \& Peng, 2013) and may also impact animals' general activity. Works of Bateson (for instance, 1979) are also in favor of such a presumption. Therefore, in the present study, we aimed to define the effects of four alkaloids (caffeine, theophylline, cocaine, atropine) on several ant biological functions in order 1) to have an idea of the impact, on human beings, of these four commonly consumed alkaloids, 2) to check if ants could be efficiently used as models for collecting information about effects of substances or treatments on living organisms, 3) to estimate if ants may be used for detecting the presence of small amount of substances in collected samples.

In this study, we focused on ten ethological and physiological parameters:

$>$ 1) The general activity of the individuals: by assessing their linear and angular speed

$>$ 2) The precision of their response: by examining their orientation towards a source of alarm pheromone.

> 3) Their response to their specific pheromones: by quantifying their response to their trail pheromone.

$>$ 4) Their food consumption: by assessing the ants present on a fresh meat food provided after two days of starvation.

5) Their tendency in accomplishing risky tasks: by assessing the ants coming onto a tower set on their foraging area.

$>$ 6) Their ability in being conditioned: by assessing their acquisition of a visual operant conditioning, and comparing the results with those previously obtained on ants having never consumed any alkaloid.

$>$ 7) Their memory: by assessing, as in a previous experiment on ants having never received any alkaloid, the time period during which they retain their acquired visual conditioning after training ended.

$>$ 8) The 'habituation' to the consumed alkaloid: by checking if, after having consumed the alkaloid during 6 days, the revealed effects on the ants' locomotion or precision of response decreased or remained unchanged.

$>$ 9) The 'dependence': by looking if individuals having consumed an alkaloid, preferred sugar water containing the alkaloid to sugar water free of it.

$>$ 10) The time period during which the effects of a given alkaloid persist after its consumption ended: by assessing the ants' locomotion or precision of response, several times, in the course of time, after having removed the alkaloid from the ants' food.

The obtained results were compared to what is known about the effects of the alkaloids used, and conclusions were drawn as for 1) the impact of these alkaloids on living organisms; 2) the potential use of ants as models for examining physiological and ethological effects of substances or treatments; 3) the possible use of ants for detecting substances in collected material.

\section{Material and Methods}

\subsection{Collection and Maintenance of Ants}

The study was made on eight colonies of $M$. sabuleti collected, in summer 2013, in two old quarries, one located at Treigne, and one in the Aise valley (Ardenne, Belgium). The ants were nesting under stones, on a field covered with small, often odorous plants. Myrmica sabuleti is a well known species: its ecology, eye morphology, visual perception, visual and olfactory conditioning, navigation system, recruitment strategy, responses to pheromones, acquisition by callow ants of adults' cognitive abilities have already been studied (M.-C. Cammaerts \& D. Cammaerts, 2012; Cammaerts, Rachidi, Bellens, \& De Doncker, 2013; Cammaerts, 2013a, 2013b, 2014, in press). The eight collected colonies were demographically identical, containing about 600 workers, one or two queens and brood (at larval stage). They were maintained in the laboratory in artificial nests made of one to three glass tubes half-filled with water, with a cotton-plug separating the ants from the water. The glass tubes were deposited in trays $(34 \mathrm{~cm} \times 23 \mathrm{~cm} \times 4 \mathrm{~cm})$, the sides of which were covered with talc to prevent 
the ants from escaping. The trays served as foraging areas, food being delivered into them. The ants were fed with sugar water provided ad libitum in a small glass tube plugged with cotton, and with cut Tenebrio molitor larvae (Linnaeus 1758) provided twice a week on a glass slide. Temperature was maintained between $18{ }^{\circ} \mathrm{C}$ and $22{ }^{\circ} \mathrm{C}$, humidity at about $80 \%$, these conditions remaining constant over the course of the study. Lighting had a constant intensity of 330 lux while caring for the ants, training and testing them. During other time periods, the lighting was dimmed to 110 lux. The electromagnetic field had an intensity of 2-3 $\mu \mathrm{W} / \mathrm{m}^{2}$.

\subsection{Acquisition of the Alkaloids; Realization of Aqueous Solutions for Ants}

One gram of caffeine and of theophylline, as well as $100 \mathrm{mg}$ of cocaine and of atropine sulfate, was provided, via the pharmacist Mr. Cardon J. (Brussels), by the manufacturer CERTA. The alkaloids were provided as a white bright powder, at the highest level of purity possible. Using a precise balance, $15 \mathrm{mg}$ of each alkaloid was prevailed and dissolved in $15 \mathrm{ml}$ of a saturated solution of brown sugar, the ants' common liquid food. The concentration in alkaloid of the solution was thus $1 / 1,000$. These solutions were given to the ants, like their usual liquid food, in a small glass tube plugged with cotton, this cotton being refreshed each two days.

\subsection{Assessment of the Ants' Linear Speed, Angular Speed and Orientation}

Ants' linear and angular speed was assessed for detecting excitation in the animals. This assessment was made on ants freely moving on their foraging area. Ants' orientation towards an isolated congener's head (the source of the ants' alarm pheromone) was assessed for examining the ants' precision of reaction. An isolated worker's head, with widely open mandibles, is a source of alarm pheromone identical to that of an alarmed worker, in terms of the dimensions of the emitting source (the mandibular glands opening) and the quantity of pheromone emitted (Cammaerts-Tricot, 1973).

Each time, such assessment was made firstly before giving alkaloid to the ants, secondly one day after the ants had drunk sugar water containing the alkaloid. For each assessment, the movement of 10 ants of each two colonies ( $\mathrm{N}=20$ ants) was analyzed.

Trajectories were recorded manually, using a water-proof marker pen, on a glass slide placed on the top of the experimental tray, set horizontally $3 \mathrm{~cm}$ above the area where the tested individuals were moving. A metronome set at 1 second was used as a timer for assessing the total time of each trajectory. Each trajectory was recorded during 5 to 10 seconds or until the ant reached the stimulus. All the trajectories were then traced (copied) with a water-proof marker pen onto transparent polyvinyl sheets (Figures 1E and 1F). These sheets could then be affixed to a PC monitor screen. The trajectories were then analyzed using specifically designed software (Cammaerts, Morel, Martino, \& Warzée, 2012). Briefly, each trajectory was defined in the software by clicking as many points as needed with the mouse. Then, the total time of the trajectory (assessed using the metronome) was entered, and feature of the trajectory could be measured (linear speed, angular speed, orientation).

The three variables used to characterize the trajectories were defined as follows:

The linear speed $(\mathrm{V})$ of an animal is the length of its trajectory divided by the time spent moving along this trajectory. It was measured in $\mathrm{mm} / \mathrm{s}$.

The angular speed (S) (i.e. the sinuosity) of an animal's trajectory is the sum of the angles, measured at each successive point of the trajectory, made by the segment 'point $\mathrm{i} \rightarrow$ point $\mathrm{i}-1$ ' and the segment 'point $\mathrm{i} \rightarrow$ point $\mathrm{i}$ +1 ', divided by the length of the trajectory. This variable was measured in angular degrees $/ \mathrm{cm}$.

The orientation $(\mathrm{O})$ of an animal towards a given point (here an ant's head) is the sum of the angles, measured at each successive point of the registered trajectory, made by the segment 'point i of the trajectory $\rightarrow$ given point' and the segment 'point $\mathrm{i} \rightarrow$ point $\mathrm{i}+1$ ' divided by the number of measured angles. This variable was measured in angular degrees. When such a variable $(\mathrm{O})$ equals $0^{\circ}$, the observed animal perfectly orients itself towards the point; when $\mathrm{O}$ equals $180^{\circ}$, the animal fully avoids the point; when $\mathrm{O}$ is lower than $90^{\circ}$, the animal has a tendency to orient itself towards the point; when $\mathrm{O}$ is larger than $90^{\circ}$, the animal has a tendency to avoid the point.

Each distribution of 20 variables was characterized by its median and its quartiles since it was not Gaussian (Tables 1, 3, 5, 7, lines 1,2), and the distribution of values obtained for ants having consumed alkaloid was statistically compared to that previously obtained for the same ants before they consumed alkaloid using the non-parametric $\chi^{2}$ test (Siegel \& Castellan, 1989, pp. 111-116). The significance threshold was set to $\alpha=0.05$.

\subsection{Assessment of the Ants' Trail Following Behavior}

This behavior was assessed for examining the ants' response to their pheromones. The trail pheromone of Myrmica ants is produced by the workers' poison gland. So, ten of these glands were isolated in $0.5 \mathrm{ml}(500 \mu \mathrm{l})$ 
hexane and stored for $15 \mathrm{~min}$ at $-25{ }^{\circ} \mathrm{C}$. To perform one experiment, $0.05 \mathrm{ml}(50 \mu \mathrm{l})$ of the solution was deposited, using a normograph pen (a pen used for drawing, hexane extract being poured inside the pen instead of ink), on a circle $(\mathrm{R}=5 \mathrm{~cm})$ pencil drawn on a piece of white paper and divided into 10 ang. deg. arcs. One minute after being prepared, the piece of paper with the artificial trail was placed in the ants' foraging area. When an ant came into contact with the trail, its movement was observed. Its response was assessed by the number of 10 ang. deg. arcs it walked without departing from the trail, even if it turned back on the trail. If an ant turned back when being in front of the trail, its response was assessed as "zero arcs walked"; when an ant crossed the trail without following it, its response equaled "one walked arc". Before testing the ants on a trail, they were observed on a circumference imbibed with $50 \mu 1$ of pure hexane and the control numbers of walked arcs were so obtained. For each control and test experiment, 20 individuals of each two used colonies were observed; 40 numbers of walked arcs were so each time recorded. Each distribution of values was characterized by its median and its quartiles, since it was not Gaussian (Tables 1, 3, 5, 7, line 3) and those obtained for ants having consumed alkaloid were statistically compared to the corresponding ones obtained for the same ants before they consumed alkaloid, this by using the non parametric $\chi^{2}$ test (Siegel \& Castellan, 1989). On such experimental trails, Myrmica workers do not deposit their trail pheromone because they do so only after having found food or a new nest site.

\subsection{Assessment of the Ants' Audacity}

Before the ants consumed alkaloid and three days after they had consumed such alkaloid, a tower built in strong white paper (Steinbach $\left.{ }^{\circledR}\right)(\mathrm{h}=4 \mathrm{~cm}$; diam $=1.5 \mathrm{~cm})$ was set on the ants' foraging area (Figure 1A), and the ants present on it were counted 10 times. The mean and the extreme values of the obtained values were established each time and the two series of values were compared using the non parametric Mann-Whitney U test (Siegel \& Castellan, 1989, pp. 128-137; Tables 1, 3, 5, 7, line 4).

\subsection{Assessment of the Ants' Consumption of Food}

Before the ants consumed a given alkaloid, and after they had consumed that alkaloid for three days, the workers present on the T. molitor larva were counted 10 times. The numbers obtained under the two kinds of food consumption were statistically compared using the Mann-Whitney $U$ test (same reference as above) and the mean as well as the extreme values of the recorded numbers were established (Tables 1, 3, 5, 7, line 5).

\subsection{Assessment of the Ants' Ability in Acquiring Operant Visual Conditioning and of the Ants' Memory}

Briefly, at a given time, a green hollow cube was set above the T. molitor larva, this time tied to the supporting piece of glass. The ants so underwent visual operant conditioning. Tests were performed in the course of the ants conditioning acquisition, then, after having removed the green cube, of their conditioning loss.

In detail, ants were collectively visually trained to a hollow green cube constructed of strong paper (Canson $®$ ) according to the instructions given in Cammaerts and Nemeghaire (2012) and set over the meat food which served as a reward (Figure 1B). The color has been analyzed to determine its wavelengths reflection (Cammaerts, 2007). The ceiling of each cube was filled unlike the four vertical faces, this allowing the ants entering the cubes. The green cube was considered to be the 'correct' choice when the ants were tested as explained below.

Ants were individually tested in a Y-shaped apparatus constructed of strong white paper according to the instructions given in M.-C. Cammaerts, Rachidi, and D. Cammaerts (2011), and set in a small tray $(30 \mathrm{~cm} \times 15$ $\mathrm{cm} \times 4 \mathrm{~cm}$ ), apart from the experimental colony's tray (Figure 1C). Each colony had its own testing design. The apparatus had its own bottom and the sides were covered with talc to prevent the ants from escaping. In the Y-apparatus, the ants deposited no trail since they were not rewarded. However, they may utilize other chemical secretions as traces. As a precaution, the floor of each Y-apparatus was changed between tests. The Y-apparatus was provided with a green cube in one or the other branch (Figure 1C). Half of the tests were conducted with the cube in the left branch and the other half with the cube in the right branch of the Y maze, and this was randomly chosen. Control experiments had previously been made on never conditioned ants, and conditioning experiments had also been previously performed on ants having never received alkaloid (Tables 1, 3, 5, 7, lines 6, 7; Cammaerts et al., 2011). Indeed, once any animals are conditioned to a given stimulus, they become no longer naïve for such an experiment. It was thus impossible, in the present study, to perform, on the same colonies, the ants' conditioning without then with the alkaloid. 

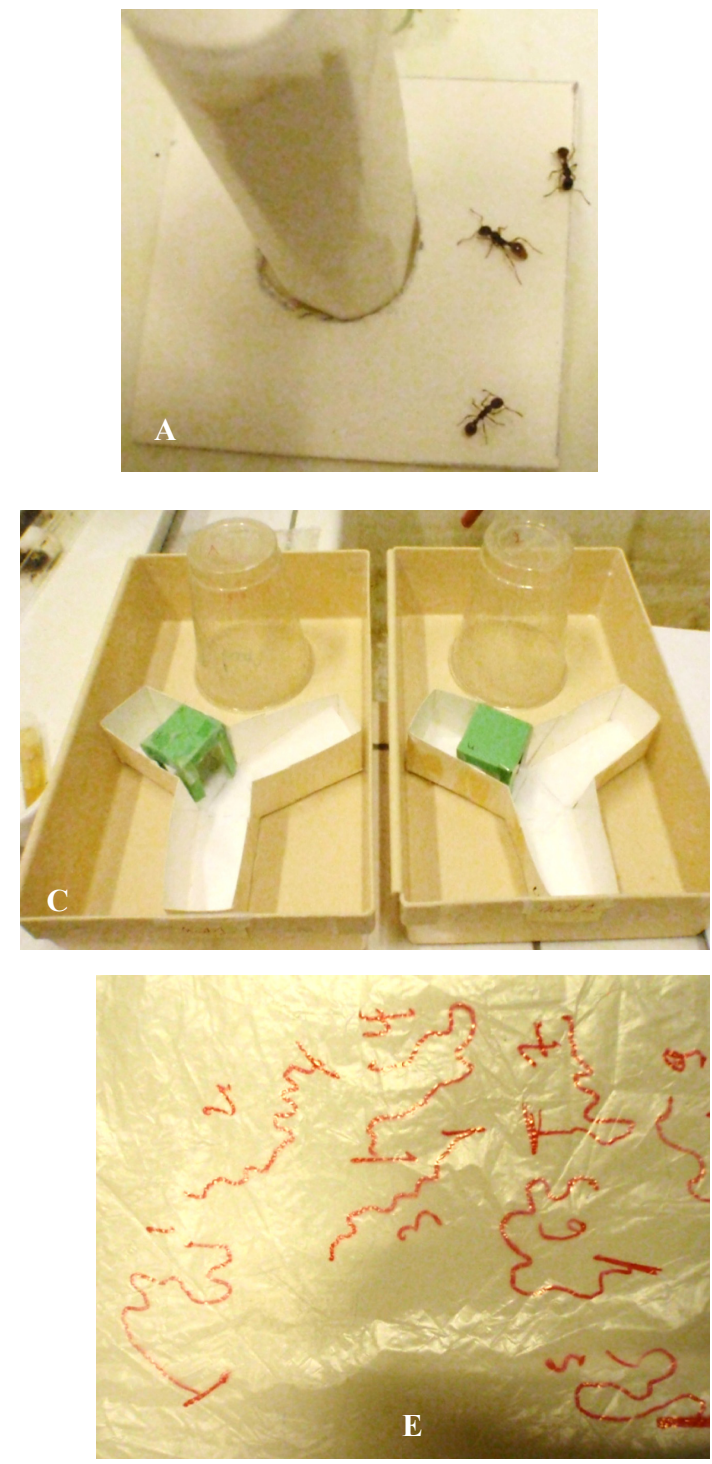

E
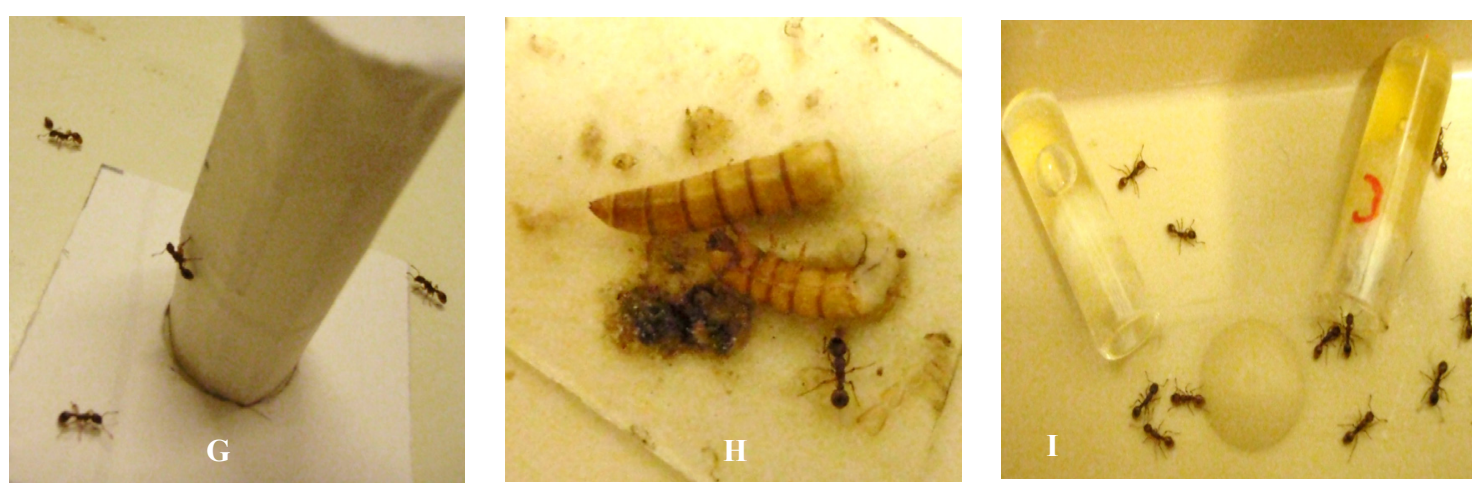

Figure 1. Selected views of the experiments

A: the tower used for assessing the ants' daring. B: two ant colonies under training to a visual cue, a green hollow cube. C: experimental apparatus used for testing ants being under operant visual conditioning. D: experimental design used for assessing the ants' dependence on an alkaloid, this one being present in the right tube for nest 1 and in the left tube for nest 2; in the present case, the alkaloid was theophylline and ants did not exhibit any dependence. E, F: recorded ants' trajectories E: under normal diet and F: after caffeine consumption. G: ants having consumed cocaine and coming onto the tower. H: ants having consumed cocaine and staying near the meat food without eating. I: ants having consumed cocaine and choosing sugar water containing this alkaloid during the test allowing revealing such dependence. 
To conduct a test on a colony, 10 workers of that colony - randomly chosen from the workers of that colony were transferred one by one to the area at the entrance of the Y-apparatus. Each transferred ant was observed until it turned either to the left or to the right in the Y-tube, and its choice was recorded. Only the first choice of the ant was recorded and this only when the ant was entirely under the cube, i.e. beyond a pencil drawn thin line indicating the entrance of a branch (Figure 1C). Afterwards, the ant was removed and transferred to a polyacetate cup, in which the rim was covered with talc, until 10 ants were so tested, this avoiding testing the same ant twice. All the tested ants were then placed back on their foraging area. For each experiment, the numbers of ants, among $10+10=20$, which turned towards the "correct" green cube, or went to the "wrong" empty branch of the Y were recorded. The percentage of correct responses for the tested ant population was so established (Tabs 1, 3, $5,7$, lines 6,7$)$. The results obtained for ants that have consumed alkaloid were compared to those obtained for ants that have never consumed such substances (Tables 1, 3, 5, 7, lines 6, 7; Figure 2) using the non parametric test of Wilcoxon (Siegel \& Castellan, 1989, pp. 87-95). For such a test, the value of N, T, and P, according to the nomenclature of the here above cited authors, are given in the results section.

\subsection{Ants' Habituation to the Consumed Alkaloid}

Four to seven days after ants had continuously consumed a given alkaloid, their linear and angular speed or their orientation towards an isolated worker's head, were assessed. The results were compared to the control ones and to those obtained after one day of alkaloid consumption using the non parametric $\chi^{2}$ test (Siegel \& Castellan, 1989; Tables 2, 4, 6, 8, line 1).

\subsection{Ants' Dependence on the Consumed Alkaloid}

After the ants had continuously consumed a given alkaloid during five to nine days, an experiment was performed to examine if they have acquired some dependence on the consumed alkaloid. Fifteen ants of each two used colonies were transferred into a small tray $(15 \mathrm{~cm} \times 7 \mathrm{~cm} \times 5 \mathrm{~cm})$, the borders of which had been covered with talc and in which laid two tubes $(\mathrm{h}=2.5 \mathrm{~cm}$, diam. $=0.5 \mathrm{~cm})$, one containing sugar water, the other sugar water + a given alkaloid (at the concentration 1/1,000), each tube being plugged with cotton (Figure 1D). In one of the trays, the tube containing the alkaloid was located on the right; in the other tray, it was located on the left. The ants drinking each liquid food were counted 12 times, the mean values being then established for each kind of food (Tables 2, 4, 6, 8, line 2). They were statistically compared to the values expected if ants randomly went drinking each kind of food, using the non parametric goodness of fit $\chi^{2}$ test (Siegel \& Castellan, 1989, pp. 45-51).

\subsection{Duration of the Effect of the Alkaloid}

Eight to twenty days after that the ants had continuously consumed a given alkaloid, the liquid food containing this alkaloid was removed from the ants' tray and replaced by sugar water free of alkaloid. This change was made at a given recorded time. After that, the ants' linear and angular speed or their orientation towards an isolated worker's head, were assessed after successive given time periods. The results revealed the decrease of the effects, on ants, of the consumed alkaloid (Tables 2, 4, 6, 8, line 3; Figure 3). Their statistical significance could be estimated via the non parametric $\chi^{2}$ test (Siegel \& Castellan, 1989, pp. 111-124).

\section{Results}

\subsection{Concerning Caffeine}

\subsubsection{Effect on Ants' Locomotion}

After having consumed caffeine for one day, the ants moved more quickly and less sinuously. These changes in locomotion were statistically significant (Table 1 , line 1 ; linear speed: $\chi^{2}=21.51, \mathrm{df}=1, \mathrm{P}<0.001$; angular speed: $\left.\chi^{2}=17.22, \mathrm{df}=2, \mathrm{P}<0.001\right)$, and obvious while observing the ants, and their recorded trajectories (Figures 1E and 1F).

\subsubsection{Effect on Ants' Precision When Reacting}

The ants' reaction to an isolated worker's head (a source of their alarm pheromone) consists in a positive orthokinesis due to the attractiveness of the alarm pheromone. Under normal diet, ants oriented themselves very well towards an isolated worker's head (median value $=38.5$ ang. deg., far lower than 90 ang. deg.). After having consumed caffeine for one day, the ants went on being attracted by their alarm pheromone (median value $=57.2$ ang. deg, still lower than 90 and deg.) but their positive orthokinesis was of lower quality than before consuming caffeine, this difference being statistically significant (Table 1 , line $2 ; \chi^{2}=9.50, \mathrm{df}=2, \mathrm{P}<0.01$ ).

\subsubsection{Effect on Ants' Response to Their Pheromones}

After a two day time period of caffeine consumption, the ants' trail following behavior (= a response to one of 
their pheromones) was similar to that exhibited before such a consumption (Table 1 , line $3 ; \chi^{2}=1.68, \mathrm{df}=2$, NS). Caffeine did not affect the ants' response to their pheromones.

\subsubsection{Effect on Ants' Audacity}

No difference could be revealed between the numbers of ants coming onto a tower (a 'risky' apparatus) before consumption of caffeine and after three days of such consumption (Table 1, line 4; Figure 1A; $\mathrm{U}=30.5, \mathrm{Z}=$ $0.105, \mathrm{P}=0.878$ ).

\subsubsection{Effect on Ants' Consumption of Food}

While consuming caffeine, statistically fewer ants eat the provided T. molitor larva (Table 1, line $5 ; \mathrm{U}=11, \mathrm{Z}=$ 2.91, $\mathrm{P}=0.002$ ). The ants did not stop eating; they only spent less time in performing this task.

\subsubsection{Effect on Ants' Conditioning Capability}

While under normal diet, M. sabuleti workers acquired $80 \%$ of operant visual conditioning in $167 \mathrm{hrs}$ ( $=7$ days), after having consumed caffeine for 5 days, they acquired a conditioning score of $80 \%$ in $23 \mathrm{hrs}$ and an exceptional score of $90 \%$ after a total of only 47 hrs (2 days). Such a difference was significant (Table 1, line 6; $\mathrm{N}=4, \mathrm{~T}=10, \mathrm{P}=0.06$; Figure 2, left part, empty and black circles).

\subsubsection{Effect on Ants' Memory}

Under normal diet, visually conditioned ants lost nearly all their conditioning in about $90 \mathrm{hrs}$ ( 2 1/3 days) and kept $10 \%$ of it during several days, even weeks (Cammaerts et al., 2011). After having consumed caffeine for seven days, the conditioned ants never lost their conditioning, still presenting a score of $80 \%$ after $46 \mathrm{hrs}$ and retaining $30 \%$ of their conditioning for 10 or more days or weeks. Such a difference was significant (Table 1, line 7; $\mathrm{N}=8, \mathrm{~T}=36, \mathrm{P}=0.004$; Figure 2, right part, empty and black circles).

\subsubsection{Ants' Habituation to Caffeine}

The ants' locomotion was examined one day and seven days after they had consumed caffeine. No difference in linear speed could be statistically detected (the ants' linear speed was even slightly larger after 7 days); the ants' sinuosity was statistically larger after 7 days than after one day (Table 2 , line 1 ; linear speed: $\chi^{2}=1.75, \mathrm{df}=2$, NS; angular speed: $\left.\chi^{2}=7.03, \mathrm{df}=1, \mathrm{P}<0.01\right)$. So, no decrease of effect occurred in the course of caffeine consumption.

Table 1. Effect of caffeine on seven physiological and ethological functions

\begin{tabular}{|c|c|c|c|c|}
\hline Functions & Variable Assessed & Normal Diet & Diet + Caffeine & Statistics \\
\hline \multirow{2}{*}{$\begin{array}{l}\text { Activity } \mathrm{n}=20 \\
\text { (locomotion) }\end{array}$} & Linear speed $\mathrm{mm} / \mathrm{sec}$ & $10.5(9.3-12.1)$ & $17.8(15.8-20.9)$ & $\mathrm{P}<0.001$ \\
\hline & Sinuosity ang.deg./cm & $142(130-165)$ & $113(93-123)$ & $\mathrm{P}<0.001$ \\
\hline $\begin{array}{l}\text { Precision of a reaction } \\
n=20\end{array}$ & $\begin{array}{l}\text { Orientation to an alarm } \\
\text { signal ang.deg. }\end{array}$ & $38.5(32.6-58.9)$ & $57.2(51.2-68.4)$ & $\mathrm{P}<0.01$ \\
\hline Response to pheromones & Trail following behavior & $C: 1(1-2)$ & $\mathrm{C}: 1(1-2)$ & NS \\
\hline $\mathrm{n}=40$ & ( $\mathrm{n}^{\circ}$ of arcs walked) & $\mathrm{T}: 10.5(7.8-18.5)$ & $\mathrm{T}: 9.0(6.0-15.0)$ & NS \\
\hline Audacity $n=10$ & $\mathrm{n}^{\circ}$ of ants on a tower & $7.7(6-9)$ & $7.5(2-13)$ & $\mathrm{P}=0.878$ \\
\hline Food consumtion $\mathrm{n}=10$ & $\begin{array}{c}\mathrm{n}^{\circ} \text { of ants eating meat } \\
\text { (mean, extrema) }\end{array}$ & $3.5(1-6)$ & $1.8(0-3)$ & $\mathrm{P}=0.002$ \\
\hline
\end{tabular}




\begin{tabular}{|c|c|c|c|c|c|c|}
\hline \multirow{15}{*}{$\begin{array}{l}\text { Learning ability } \\
n=120+20=140\end{array}$} & \multirow{15}{*}{$\%$ of correct responses } & * C: $61 / 59$ & $50 \%$ & & & \multirow{15}{*}{$\begin{array}{c}\mathrm{N}=4, \mathrm{~T}=10 \\
\mathrm{P}=0.06\end{array}$} \\
\hline & & 7 hrs 61/59 & $51 \%$ & 7 hrs $15 / 5$ & $75 \%$ & \\
\hline & & 23 hrs 68/52 & $57 \%$ & $23 \mathrm{hrs} \mathrm{16/4}$ & $80 \%$ & \\
\hline & & 30 hrs 68/52 & $57 \%$ & 30 hrs 17/3 & $85 \%$ & \\
\hline & & $47 \mathrm{hrs} 76 / 44$ & $63 \%$ & 47 hrs $18 / 2$ & $90 \%$ & \\
\hline & & 55 hrs 75/45 & $63 \%$ & & & \\
\hline & & 71 hrs $80 / 40$ & $67 \%$ & & & \\
\hline & & $79 h r s$ 79/41 & $66 \%$ & & & \\
\hline & & 95 hrs $84 / 36$ & $70 \%$ & & & \\
\hline & & $103 \mathrm{hrs} 82 / 38$ & $68 \%$ & & & \\
\hline & & 118 hrs $87 / 33$ & $73 \%$ & & & \\
\hline & & 127 hrs $83 / 37$ & $69 \%$ & & & \\
\hline & & 145 hrs 94/26 & $78 \%$ & & & \\
\hline & & $167 \mathrm{hrs} 97 / 23$ & $81 \%$ & & & \\
\hline & & 215 hrs $96 / 24$ & $80 \%$ & & & \\
\hline \multirow{11}{*}{$\begin{array}{c}\text { Memory } \\
n=120+20=140\end{array}$} & \multirow{11}{*}{$\%$ of correct responses } & *6 hrs $87 / 33$ & $73 \%$ & 6 hrs $17 / 3$ & $85 \%$ & \multirow{11}{*}{$\begin{array}{c}\mathrm{N}=8, \mathrm{~T}=36 \\
\mathrm{P}=0.004\end{array}$} \\
\hline & & 20 hrs $92 / 28$ & $77 \%$ & $20 \mathrm{hrs} 17 / 3$ & $85 \%$ & \\
\hline & & 46 hrs $81 / 39$ & $68 \%$ & 46 hrs $18 / 2$ & $90 \%$ & \\
\hline & & 71 hrs $76 / 44$ & $63 \%$ & 71 hrs 16/4 & $80 \%$ & \\
\hline & & $95 \mathrm{hrs} 71 / 49$ & $59 \%$ & $95 \mathrm{hrs} \mathrm{15/5}$ & $75 \%$ & \\
\hline & & 116 hrs $72 / 48$ & $60 \%$ & 116 hrs $15 / 5$ & $75 \%$ & \\
\hline & & 143 hrs 69/51 & $58 \%$ & 143 hrs $17 / 3$ & $85 \%$ & \\
\hline & & $166 \mathrm{hrs} 72 / 48$ & $60 \%$ & 166 hrs 16/4 & $80 \%$ & \\
\hline & & & & 189 hrs 16/4 & $80 \%$ & \\
\hline & & & & $214 h r s 16 / 4$ & $80 \%$ & \\
\hline & & & & 237 hrs 16/4 & $80 \%$ & \\
\hline
\end{tabular}

Details are given in the text. Briefly, caffeine increased ants' linear speed, learning ability and memory, unchanged their audacity and their response to pheromone, decreased the precision of their response and their food consumption. Results about conditioning and memory are graphically presented in Figure 2 (black circles). * = results obtained by Cammaerts et al. (2011).

\subsubsection{Ants' Dependence on Caffeine}

The appropriate test was performed after that the ants had consumed caffeine for nine days. Meanly $48.1 \%$ of ants chose the sugar food containing caffeine and $51.9 \%$ the food free of the alkaloid. The numbers obtained (79 vs 81) did not statistically differ from those expected if ants chose the provided foods at random (80vs 80) (Table 2, line 2; $\chi^{2}=0.006, \mathrm{df}=1,0.90<\mathrm{P}<0.95$, NS). Thus, ants did not become dependent on caffeine consumption.

\subsubsection{Time Period During Which Consumed Caffeine Affected the Ants}

Twenty days after ants had consumed caffeine, their sugar food containing the alkaloid was removed and replaced by sugar food free of this substance. The ants' trajectories were recorded $1,2 \frac{1}{2}, 4 \frac{1}{2}$, and $8 \mathrm{hrs}$ later. The ants' linear speed decreased in the course of time, revealing so a decrease of the effect of caffeine (Table 2, line 3). This decrease may be a negative exponential function of the time (Figure 3, black circles and dotted line). After one day, the ants' linear speed equaled $11.4 \mathrm{~mm} / \mathrm{sec}$ and their angular speed 120 ang.deg./cm, values which were not identical to though statistically not different from the control ones (linear speed: $\chi^{2}=0.42, \mathrm{df}=2, \mathrm{P} \approx$ $0.80, \mathrm{NS}$; angular speed: $\chi^{2}=1.75, \mathrm{df}=2,0.30<\mathrm{P}<0.50, \mathrm{NS}$ ). 


\subsubsection{Other Observed Effects}

One hour after ants had consumed caffeine, a few ones appeared to suffer just like if they were very thirsty. We gave tap water to the ants, each day, on their foraging area. Ants came drinking and no longer suffered.

Table 2. Habituation to caffeine, dependence on its consumption, and duration of its effect on ants

\begin{tabular}{|c|c|c|}
\hline Effect Studied & Variable Assessed & Numerical Results \\
\hline Habituation & Linear speed $\mathrm{mm} / \mathrm{sec}$ & $18.7(17.8-20.2)$ vs 1 day: NS \\
\hline (after 7 days) & Sinuosity ang.deg./cm & 132 (105-153) vs 1 day: $0.001<\mathrm{P}<001$ \\
\hline $\begin{array}{l}\text { Dependence } \\
\text { (12 counts) }\end{array}$ & $\begin{array}{c}\text { choices of sugar water }+ \text { caffeine } \\
\text { vs sugar water }\end{array}$ & $\begin{array}{l}\text { nest } 1: 51 \text { ants } v s 44 \text { ants }=51 / 96=53.1 \% \\
\text { nest 2: } 28 \text { ants } v s 37 \text { ants }=28 / 65=43.1 \%\end{array}$ \\
\hline \multirow{4}{*}{ Duration of effect } & \multirow{4}{*}{$\begin{array}{l}\text { Linear }(\mathrm{mm} / \mathrm{sec}) \text { and angular } \\
\quad \text { (ang.deg./cm) speed }\end{array}$} & T 1hrs $20.3(17.8-21.8) \quad 125(102-133)$ \\
\hline & & $T 2^{1 / 2 h r s} \quad 18.7(17.2-20.7) \quad 125(103-138)$ \\
\hline & & T 41/2hrs $\quad 16.9(14.8-19.2) \quad 126(108-144)$ \\
\hline & & T 8hrs $\quad 13.8(12.6-16.3) \quad 133(117-154)$ \\
\hline
\end{tabular}

Details are given in the text. Briefly, ants did not become habituated to nor dependent on caffeine and the effects of the alkaloid exponentially decreased in the course of time, ending in about $11-13$ hours. The latter observation is also graphically presented in Figure 3 (black circles).

\subsection{Concerning Theophylline}

\subsubsection{Effect on Ants' Locomotion}

After having drunk, for one day, sugar water containing theophylline, M. sabuleti workers obviously and statistically walked more rapidly than usually $(21.4 \mathrm{~mm} / \mathrm{sec} v s 13.0 \mathrm{~mm} / \mathrm{sec} ; \mathrm{p}<0.001)$ but not statistically less sinuously (Table 3, line 1; linear speed: $\chi^{2}=18.09$, $\mathrm{df}=1, \mathrm{P}<0.0001$; angular speed: $\chi^{2}=1.79, \mathrm{df}=2,0.30<\mathrm{P}$ $<0.50, \mathrm{NS})$. In fact, the ants moved very quickly, then stopped, then moved again rapidly.

\subsubsection{Effect on Ants' Precision When Reacting}

Under theophylline consumption, the ants' orientation by orthokinesis towards a source of alarm pheromone was only slightly and not statistically lower than without consuming the alkaloid (Table 3 , line $2 ; \chi^{2}=2.09$, df $=2$, $0.30<\mathrm{P} 0.50, \mathrm{NS})$.

\subsubsection{Effect on Ants' Response to Their Pheromones}

Under theophylline consumption, the ants less efficiently followed a trail (9.5 vs 16.5 arcs walked along the circular trail) but the variability of the ants' responses was so large that this decrease in efficiency was not statistically significant (Table 3 , line $3 ; \chi^{2}=3.23, \mathrm{df}=3,0.30<\mathrm{P} 0.50$, NS).

\subsubsection{Effect on Ants' Audacity}

After having consumed theophylline for five days, as many ants moved onto a tower (a risky apparatus) as before consuming such an alkaloid (Table 3, line $4 ; \mathrm{U}=602, \mathrm{Z}=-0.66, \mathrm{P}=0.514$ ). The ants' behavior in front of the apparatus was exactly the same before and after consumption of theophylline: hesitation, coming then moving away, stopping, and cleaning antennae.

\subsubsection{Effect on Ants' Consumption of Food}

Under consumption of theophylline, the ants eating the T. molitor larva were less, but not statistically lees, numerous than those eating that meat food before receiving the alkaloid (meanly $1.8 v s$ 2.3) (Table 3, line 5; $\mathrm{U}=$ $38.52, \mathrm{Z}=0.832, \mathrm{P}=0.393)$. In fact, the ants spent less time on the food site, this being probably due to their increase of locomotion.

\subsubsection{Effect on Ants' Conditioning Capability}

Under normal diet, after $30 \mathrm{hrs}$ of training, the ants presented a conditioning score of $57 \%$; under theophylline consumption, they reached, in the same time period, the exceptional conditioning score of $90 \%$ (Table 3, line 6; $\mathrm{N}=4, \mathrm{~T}=10, \mathrm{P}=0.06$; Figure 2, left part, black triangles $v$ s empty circles). The tested ants' behavior clearly reflected such a result: they scarcely hesitated and went rapidly under the hollow green cube. 
Table 3. Effect of theophylline on seven physiological and ethological functions

\begin{tabular}{|c|c|c|c|c|c|c|}
\hline Functions & Variable Assessed & \multicolumn{2}{|c|}{ Normal Diet } & \multicolumn{2}{|c|}{ Diet+Theophylline } & Statistics \\
\hline Activity $n=20$ & Linear speed $\mathrm{mm} / \mathrm{sec}$ & \multicolumn{2}{|c|}{$13.0(11.9-14.3)$} & \multicolumn{2}{|c|}{ 21.4(19.2-23.6) } & $\mathrm{P}<0.001$ \\
\hline (locomotion) & Sinuosity ang.deg./cm & \multicolumn{2}{|c|}{$115(99-151)$} & \multicolumn{2}{|c|}{$111(77-137)$} & NS \\
\hline $\begin{array}{l}\text { Precision of a reaction } \\
\qquad \mathrm{n}=20\end{array}$ & $\begin{array}{l}\text { Orientation to an alarm } \\
\text { signal ang.deg. }\end{array}$ & \multicolumn{2}{|c|}{$47.3(35.7-52.7)$} & \multicolumn{2}{|c|}{$55.2(43.2-62.7)$} & NS \\
\hline \multirow{2}{*}{$\begin{array}{c}\text { Response to } \\
\text { pheromones } n=40\end{array}$} & Trail following behavior & \multicolumn{2}{|c|}{ C: $1(1-2)$} & \multicolumn{2}{|c|}{$C: 1(1-2)$} & NS \\
\hline & ( $\mathrm{n}^{\circ}$ of arcs walked) & \multicolumn{2}{|c|}{$\mathrm{T}: 16.5(8.0-23.5)$} & \multicolumn{2}{|c|}{$\mathrm{T}: 9.5(3.8-22.5)$} & NS \\
\hline Audacity $n=10$ & $\mathrm{n}^{\circ}$ of ants on a tower & \multicolumn{2}{|c|}{$1.4(0-3)$} & \multicolumn{2}{|c|}{$1.3(0-2)$} & $\mathrm{P}=0.514$ \\
\hline $\begin{array}{l}\text { Food consumption } \\
\qquad \mathrm{n}=10\end{array}$ & $\begin{array}{c}\mathrm{n}^{\circ} \text { of ants eating meat } \\
\text { (mean, extrema) }\end{array}$ & \multicolumn{2}{|c|}{$2.3(0-3)$} & \multicolumn{2}{|c|}{$1.8(0-3)$} & $P=0.393$ \\
\hline \multirow{15}{*}{$\begin{array}{l}\text { Learning ability } \\
n=120+20=140\end{array}$} & \multirow{15}{*}{$\%$ of correct responses } & * C: $61 / 59$ & $50 \%$ & & & \multirow{15}{*}{$\begin{array}{c}\mathrm{N}=4, \mathrm{~T}=10 \\
\mathrm{P}=0.06\end{array}$} \\
\hline & & 7 hrs $61 / 59$ & $51 \%$ & 7 hrs $15 / 5$ & $75 \%$ & \\
\hline & & 23 hrs 68/52 & $57 \%$ & 23 hrs $17 / 3$ & $85 \%$ & \\
\hline & & 30 hrs $68 / 52$ & $57 \%$ & 30 hrs $18 / 2$ & $90 \%$ & \\
\hline & & 47 hrs $76 / 44$ & $63 \%$ & \multirow[t]{11}{*}{47 hrs $17 / 3$} & \multirow[t]{11}{*}{$85 \%$} & \\
\hline & & 55 hrs $75 / 45$ & $63 \%$ & & & \\
\hline & & 71 hrs $80 / 40$ & $67 \%$ & & & \\
\hline & & $79 h r s$ 79/41 & $66 \%$ & & & \\
\hline & & 95 hrs $84 / 36$ & $70 \%$ & & & \\
\hline & & $103 \mathrm{hrs} 82 / 38$ & $68 \%$ & & & \\
\hline & & 118 hrs $87 / 33$ & $73 \%$ & & & \\
\hline & & $127 h r s 83 / 37$ & $69 \%$ & & & \\
\hline & & $145 \mathrm{hrs} 94 / 26$ & $78 \%$ & & & \\
\hline & & $167 \mathrm{hrs} 97 / 23$ & $81 \%$ & & & \\
\hline & & $215 \mathrm{hrs} 96 / 24$ & $80 \%$ & & & \\
\hline \multirow{11}{*}{$\begin{array}{c}\text { Memory } \\
n=120+20=140\end{array}$} & \multirow{11}{*}{$\%$ of correct responses } & *6 hrs 87/33 & $73 \%$ & $6 \mathrm{hrs} 17 / 3$ & $85 \%$ & \multirow{11}{*}{$\begin{array}{l}\mathrm{N}=8, \mathrm{~T}=36 \\
\mathrm{P}=0.004\end{array}$} \\
\hline & & 20 hrs $92 / 28$ & $77 \%$ & 20 hrs $17 / 3$ & $85 \%$ & \\
\hline & & 46 hrs $81 / 39$ & $68 \%$ & 46 hrs $18 / 2$ & $90 \%$ & \\
\hline & & 71 hrs 76/44 & $63 \%$ & $71 \mathrm{hrs} 18 / 2$ & $90 \%$ & \\
\hline & & 95 hrs $71 / 49$ & $59 \%$ & $95 \mathrm{hrs} \mathrm{16/4}$ & $80 \%$ & \\
\hline & & $116 \mathrm{hrs} 72 / 48$ & $60 \%$ & 116 hrs $17 / 3$ & $85 \%$ & \\
\hline & & $143 \mathrm{hrs} 69 / 51$ & $58 \%$ & 143 hrs $17 / 3$ & $85 \%$ & \\
\hline & & $166 h r s 72 / 48$ & $60 \%$ & $166 \mathrm{hrs} 17 / 3$ & $85 \%$ & \\
\hline & & & & 189 hrs $17 / 3$ & $85 \%$ & \\
\hline & & & & $214 \mathrm{hrs} 17 / 3$ & $85 \%$ & \\
\hline & & & & $237 \mathrm{hrs} 18 / 2$ & $90 \%$ & \\
\hline
\end{tabular}

Details are given in the text. Briefly, theophylline increased the ants' linear speed, learning ability and memory, unchanged their response to pheromones and their audacity, slightly decreased the precision of their reaction and their food consumption. Results relative to the conditioning and the memory are graphically presented in Figure 2 (black triangles). * = results obtained by Cammaerts et al. (2011). 


\subsubsection{Effect on Ants' Memory}

While under normal diet, the ants presented a conditioning score of $59 \% 95 \mathrm{hrs}$ after training ended, under theophylline consumption, the ants still presented a score of $80 \%$ after the same time period without training (Table 3, line $7 ; \mathrm{N}=8, \mathrm{~T}=36, \mathrm{P}=0.004$ ). Under normal diet, the ants retained $10 \%$ of their conditioning after a few days; under theophylline consumption, they retained 35\%-40\% of their conditioning for at least 10 days (Figure 2, right part, black triangles $v s$ empty circles).

\subsubsection{Ants' Habituation to Theophylline}

After seven days of theophylline consumption, the ants' linear speed was a little higher than and the ants' angular speed was similar to those presented after one day of this alkaloid consumption (Table 4 , line 1 ; linear speed: $\chi^{2}$ $=8.01, \mathrm{df}=2, \mathrm{P}<0.02$; angular speed: $\chi^{2}=0.92, \mathrm{df}=2,0.50<\mathrm{P}<0.70$, NS). No ants' habituation to theophylline could so be detected.

\subsubsection{Ants' Dependence on Theophylline}

During the appropriate test performed after the ants had consumed theophylline for nine days, similar numbers of ants went drinking the sugar water containing the alkaloid and the sugar water free of it (Table 4 , line 2 ). The numbers obtained (37vs 40) did not statistically differ from those expected if ants chose the two kinds of sugar food at random (38.5 vs 38.5) $\left(\chi^{2}=0.03, \mathrm{df}=1,0.80<\mathrm{P}<0.90\right.$, NS). So, no dependence on theophylline consumption could be detected.

\subsubsection{Time Period During Which Consumed Theophylline Affected the Ants}

Theophylline was removed from the ants' food after fifteen days of consumption. No decrease of effect was observed during the first four hours. Then, a slow decrease was revealed, the effect of the alkaloid being yet detectable after 15 hours (Table 4, line 3; linear speed after 15 hrs: $\chi^{2}=8.22, \mathrm{df}=2, \mathrm{P}<0.02$ ). An entire loss of this effect could take about $24 \mathrm{hrs}$ to $30 \mathrm{hrs}$ (Figure 3, black triangles). The curve of the loss of effect might be sigmoid.

\subsubsection{Other Observed Effects}

To avoid ants' suffering, we gave them tap water each day, on their foraging area.

Table 4. Habituation to theophylline, dependence on its consumption, and duration of its effect on ants

\begin{tabular}{|c|c|c|}
\hline Effect Studied & Variable Assessed & Numerical Results \\
\hline Habituation & Linear speed $\mathrm{mm} / \mathrm{sec}$ & $23.2(20.7-26.5)$ vs 1 day: NS \\
\hline (after 7 days) & Sinuosity ang.deg./cm & $106(92-122)$ vs 1 day: NS \\
\hline $\begin{array}{l}\text { Dependence } \\
\text { (12 counts) }\end{array}$ & $\begin{array}{l}\text { ants on sugar water }+ \\
\text { theophylline } v s \text { sugar water }\end{array}$ & $\begin{array}{l}\text { nest } 1: 19 \text { ants } v s 22 \text { ants }=19 / 41=46.3 \% \\
\text { nest } 2: 18 \text { ants } v \text { s } 18 \text { ants }=18 / 36=50.0 \%\end{array}$ \\
\hline \multirow{8}{*}{ Duration of effect } & \multirow{8}{*}{$\begin{array}{l}\text { Linear }(\mathrm{mm} / \mathrm{sec}) \text { and angular } \\
\quad \text { (ang.deg./cm) speed }\end{array}$} & T lhrs 22.5(21.7-23.2) 98(85-117) \\
\hline & & $T 2^{1 / 2 h r s} 23.3(20.7-24.9) \quad 95(85-113)$ \\
\hline & & $T 4^{1 / 2 h}$ hs 21.3(19.0-22.8) $101(85-110)$ \\
\hline & & $T 7^{1 / 2 h r s ~ 17.2(15.5-18.5) \quad 132(117-145)}$ \\
\hline & & T 10hrs $\quad 17.8(14.5-20.0) \quad 106(90-151)$ \\
\hline & & $T 12^{1 / 2 h r s ~ 16.7(14.3-17.8) \quad 114(104-128)}$ \\
\hline & & T 15hrs 15.6(14.0-18.5) 113(105-123) \\
\hline & & T $28 \mathrm{hrs} 14.4(13.3-17.3) \quad 99(89-115)$ \\
\hline
\end{tabular}

Details are given in the text. Briefly, ants did not become habituated to nor dependent on theophylline and the effects of this alkaloid decreased sigmoidally, after a latency period of four hours, in about twenty hours. The latter observation is also graphically presented in Figure 3 (black triangles). 


\subsection{Concerning Cocaine}

\subsubsection{Effect on Ants' Locomotion}

After having consumed cocaine for one day, the ants moved more slowly, what was obvious and statistically significant (Table 5, line $1 ; \chi^{2}=15, \mathrm{df}=2, \mathrm{P}<0.001$ ).

\subsubsection{Effect on Ants' Precision When Reacting}

Under normal diet, ants oriented themselves very well towards an isolated worker's head (median value $=36.1$ ang. deg., far lower than 90 ang. deg., Table 5, line 2). After having consumed cocaine for one day, the ants went on being attracted by their alarm pheromone since the median value of their orientation was still lower than 90 ang. deg., but their positive orthokinesis was of lower quality since the median value of their orientation equaled 61.1 ang. deg. This difference in the ants' precision of reaction was statistically significant (Table 5, line $2 ; \chi^{2}=$ $7.04, \mathrm{df}=2, \mathrm{P} \approx 0.02$ ).

\subsubsection{Effect on Ants' Response to Their Pheromones}

After having consumed cocaine for two days, the ants walked less efficiently along a trail (the median value equaled 5.5 arcs while, under normal diet, it equaled 11.5 arcs). Such a difference was statistically significant (Table 5, line $3 ; \chi^{2}=13.34, \mathrm{df}=3, \mathrm{P}=0.001$ ).

\subsubsection{Effect on Ants' Audacity}

The numbers of ants coming onto a tower (a 'risky' apparatus) before consumption of cocaine was low (1.3), but after three days of such consumption, it was statistically larger (4.5; Table 5, line 4; $\mathrm{U}=266.5, \mathrm{Z}=-2.71, \mathrm{P}=$ 0.006 ; Figure $1 \mathrm{G})$.

\subsubsection{Effect on Ants' Consumption of Food}

The number of ants eating the provided T. molitor larva was statistically lower while ants consumed cocaine (Table 5, line 5; $U=150, Z=4.43, P=000003$ ). Generally, the ants came onto the meat food site but stayed there, motionless, without eating (Figure 1H).

\subsubsection{Effect on Ants' Conditioning Capability}

While under normal diet, M. sabuleti workers acquired about $63 \%$ of operant visual conditioning in $50 \mathrm{hrs}$ and reach a score of $80 \%$ in about $167 \mathrm{hrs}(=7$ days), after having consumed cocaine for six days, they could never acquire any visual conditioning. The ants presented a typical behavior in the testing apparatus: when reaching the choice space, they generally stopped, turned their head to the right then to the left, walked a little forward, then turned back; in other words, they hesitated during several minutes, before going either to their right or to their left. Their mean conditioning score equaled $40 \%-55 \%$ even after $127 \mathrm{hrs}$ of training. Such a result was highly significant (Table 5, line 6; $\mathrm{N}=11, \mathrm{~T}=66, \mathrm{P}=0.0005$; Figure 2, left part, empty circles and squares).

\subsubsection{Effect on Ants' Memory}

Since after having consumed cocaine for six days, the ants could never retain (memorized) the presented visual cue, the study of their memory was impossible. The conclusion could be that eventually only very short term memory occurred, while long-lasting memory could no longer be acquired under cocaine consumption (Table 5, line 7). Such a result could be estimated as being significant.

\subsubsection{Ants' Habituation to Cocaine}

The ants' locomotion was examined one day (see above) and four days after they had consumed the alkaloid. After cocaine consumption, the ants' linear speed was no longer lower than under normal diet (Table 6, line 1; linear speed compared to the control one: $\left.\chi^{2}=1.82, \mathrm{df}=2,0.30<\mathrm{P}<0.50, \mathrm{NS}\right)$. Consequently, the effect of cocaine on ants decreased in the course of that alkaloid consumption. This was obvious while looking to the ants, and this means that the ants became habituated to such alkaloid consumption.

\subsubsection{Ants' Dependence on Cocaine}

The appropriate test was performed after the ants had consumed cocaine for five days. Meanly $80.5 \%$ of ants chose the sugar food containing cocaine, while only $19.5 \%$ chose the food free of the alkaloid. The numbers obtained (52 vs 11) statistically differed from those expected if ants chose the provided foods at random (31.5 vs 31.5) (Table 6, line $2 ; \chi^{2}=26.68, \mathrm{df}=1, \mathrm{P}<0.001$ ). Such a result was obvious while testing the ants (Figure 1I). The ants having consumed cocaine actively searched for food containing this alkaloid; they thus became dependent on cocaine consumption. 
Table 5. Effect of cocaine on seven physiological and ethological functions

\begin{tabular}{|c|c|c|c|c|c|c|}
\hline Functions & Variable Assessed & \multicolumn{2}{|c|}{ Normal Diet } & \multicolumn{2}{|c|}{ Diet + Cocaine } & Statistics \\
\hline Activity $n=20$ & Linear speed $\mathrm{mm} / \mathrm{sec}$ & \multicolumn{2}{|c|}{$13.0(11.6-14.1)$} & \multicolumn{2}{|c|}{$10.9(9.9-11.6)$} & $\mathrm{P}<0.001$ \\
\hline (locomotion) & Sinuosity ang.deg./cm & \multicolumn{2}{|c|}{$138(108-164)$} & \multicolumn{2}{|c|}{$126(113-143)$} & NS \\
\hline $\begin{array}{c}\text { Precision of a reaction } \\
n=20\end{array}$ & $\begin{array}{l}\text { Orientation to an alarm } \\
\text { signal ang.deg. }\end{array}$ & \multicolumn{2}{|c|}{$36.1(27.7-45.3)$} & \multicolumn{2}{|c|}{$61.1(37.5-80.9)$} & $\mathrm{P} \approx 0.02$ \\
\hline \multirow{2}{*}{$\begin{array}{c}\text { Response to } \\
\text { pheromones } n=40\end{array}$} & Trail following behavior & \multicolumn{2}{|c|}{$\mathrm{C}: 1(1-2)$} & \multicolumn{2}{|l|}{$\mathrm{C}: 1(1-1)$} & NS \\
\hline & ( $\mathrm{n}^{\circ}$ of arcs walked) & \multicolumn{2}{|c|}{$\mathrm{T}: 11.5(8.0-18.0)$} & \multicolumn{2}{|c|}{$\mathrm{T}: 5.5(3.0-12.3)$} & $\mathrm{P}=0.001$ \\
\hline Audacity $n=15$ & $\mathrm{n}^{\circ}$ of ants on a tower & \multicolumn{2}{|c|}{$1.3(0-3)$} & \multicolumn{2}{|l|}{$4.5(1-5)$} & $\mathrm{P}=0.006$ \\
\hline $\begin{array}{l}\text { Food consumption } \\
\qquad \mathrm{n}=15\end{array}$ & $\begin{array}{c}\mathrm{n}^{\circ} \text { of ants eating meat } \\
\text { (mean, extrema) }\end{array}$ & \multicolumn{2}{|c|}{$2.2(1-3)$} & \multicolumn{2}{|l|}{$1.6(0-2)$} & $\mathrm{P}=0.000003$ \\
\hline \multirow{15}{*}{$\begin{array}{l}\text { Learning ability } \\
\mathrm{n}=120+20=140\end{array}$} & \multirow{15}{*}{$\%$ of correct responses } & $* \mathrm{C}: 61 / 59$ & $50 \%$ & & & \multirow{15}{*}{$\begin{array}{l}\mathrm{N}=11, \mathrm{~T}=66 \\
\mathrm{P}=0.0005\end{array}$} \\
\hline & & 7 hrs 61/59 & $51 \%$ & 7 hrs 10/10 & $50 \%$ & \\
\hline & & 23 hrs 68/52 & $57 \%$ & 23 hrs 11/9 & $55 \%$ & \\
\hline & & 30 hrs 68/52 & $57 \%$ & 30 hrs $9 / 11$ & $45 \%$ & \\
\hline & & 47 hrs 76/44 & $63 \%$ & 47 hrs $10 / 10$ & $50 \%$ & \\
\hline & & 55 hrs 75/45 & $63 \%$ & 55 hrs 11/9 & $55 \%$ & \\
\hline & & 71 hrs 80/40 & $67 \%$ & 71 hrs 11/9 & $55 \%$ & \\
\hline & & $79 h r s$ 79/41 & $66 \%$ & $79 h r s 8 / 12$ & $40 \%$ & \\
\hline & & 95 hrs $84 / 36$ & $70 \%$ & 95 hrs 10/10 & $50 \%$ & \\
\hline & & 103 hrs $82 / 38$ & $68 \%$ & 103 hrs $9 / 11$ & $45 \%$ & \\
\hline & & 118 hrs $87 / 33$ & $73 \%$ & 118 hrs $10 / 10$ & $50 \%$ & \\
\hline & & 127 hrs $83 / 37$ & $69 \%$ & \multirow{4}{*}{\multicolumn{2}{|c|}{127 hrs $10 / 10 \quad 50 \%$}} & \\
\hline & & 145 hrs 94/26 & $78 \%$ & & & \\
\hline & & 167 hrs 97/23 & $81 \%$ & & & \\
\hline & & 215 hrs 96/24 & $80 \%$ & & & \\
\hline \multirow{8}{*}{$\begin{array}{c}\text { Memory } \\
\mathrm{n}=120+20=150\end{array}$} & \multirow{8}{*}{$\%$ of correct responses } & *6 hrs $87 / 33$ & $73 \%$ & \multirow{8}{*}{\multicolumn{2}{|c|}{$\begin{array}{l}\text { This could not be } \\
\text { studied since ants } \\
\text { never retained the } \\
\text { presented cue }\end{array}$}} & \\
\hline & & 20 hrs $92 / 28$ & $77 \%$ & & & \\
\hline & & 46 hrs $81 / 39$ & $68 \%$ & & & \\
\hline & & 71 hrs 76/44 & $63 \%$ & & & \\
\hline & & 95 hrs $71 / 49$ & $59 \%$ & & & \\
\hline & & 116 hrs $72 / 48$ & $60 \%$ & & & \\
\hline & & 143 hrs 69/51 & $58 \%$ & & & \\
\hline & & 166 hrs $72 / 48$ & $60 \%$ & & & \\
\hline
\end{tabular}

Details are given in the text. Briefly, cocaine decreased ants' linear speed, the precision of their response, their response to pheromone, and their food consumption; it increased their audacity. Under this alkaloid consumption, ants became unable to memorize a visual cue. The latter result is also graphically presented in Figure 2 (empty squares). * = results obtained by Cammaerts et al. (2011).

\subsubsection{Time Period during Which Consumed Cocaine Affected the Ants}

After having received cocaine for six days, the ants received no cocaine during one day, then again sugar water containing this alkaloid. They were numerous in coming drinking this liquid food. One hour later, the ants' locomotion was assessed, and just after, at $\mathrm{t}=0 \mathrm{hrs}$, the food containing cocaine was replaced by sugar water free of this alkaloid. The ants' locomotion was then assessed after $1 \mathrm{hrs}, 2 \frac{1}{2} \mathrm{hrs}, 4 \frac{1}{2} \mathrm{hrs}, 7 \frac{1}{2} \mathrm{hrs}$ and $10 \mathrm{hrs}$. During 
the first hour, effects of cocaine slightly decreased. Then, they rapidly decreased during the $2-3$ following hours, and went on decreasing during $1-2$ more hours. After $2 \frac{1}{2} \mathrm{hrs}$, the ants' linear speed was already statistically similar to the control one $\left(\chi^{2}=0.15, \mathrm{df}=2,0.90<\mathrm{P}<0.95\right.$, NS). So, the effects of cocaine vanished (probably sigmoidally) in 4 to 5 hours (Table 6 , line 3; Figure 3, empty squares).

Table 6. Habituation to cocaine, dependence on its consumption, and duration of its effect on ants

\begin{tabular}{|c|c|c|}
\hline Effect Studied & Variable Assessed & Numerical Results \\
\hline \multirow{4}{*}{$\begin{array}{l}\text { Habituation } \\
\text { (after } 7 \text { days) }\end{array}$} & \multirow{4}{*}{$\begin{array}{l}\text { Linear speed } \mathrm{mm} / \mathrm{sec} \\
\text { Sinuosity ang.deg./cm }\end{array}$} & $14.6(12.7-17.3) \quad$ vs 1 day: $\mathrm{p}<0.001$ \\
\hline & & $v s$ control: NS \\
\hline & & $115(109-128) \quad$ vs 1 day: NS \\
\hline & & vs control: NS \\
\hline \multirow{2}{*}{$\begin{array}{l}\text { Dependence } \\
\text { ( } 20 \text { counts) }\end{array}$} & \multirow{2}{*}{$\begin{array}{c}\text { choices of sugar water +cocaine } v s \\
\text { sugar water }\end{array}$} & nest 1: 18 ants $v s \quad 8$ ants $=18 / 26=69.2 \%$ \\
\hline & & nest $2: 34$ ants $v s \quad 3$ ants $=34 / 37=91.9 \%$ \\
\hline \multirow{6}{*}{ Duration of effect } & \multirow{6}{*}{$\begin{array}{l}\text { Linear }(\mathrm{mm} / \mathrm{sec}) \text { and angular } \\
\quad \text { (ang.deg./cm) speed }\end{array}$} & TOhrs $\quad 8.8(8.1-9.7) \quad 130(117-149)$ \\
\hline & & T lhrs $\quad 9.4(8.3-9.9) \quad 137(129-155)$ \\
\hline & & $T 2^{1 / 2} h r s \quad 12.0(11.5-14.0) \quad 124(107-135)$ \\
\hline & & $T 4^{1} / 2 h r s \quad 13.0(11.8-14.6) \quad 123(97-154)$ \\
\hline & & $T 71 / 2 h r s \quad 14.0(12.0-15.2) \quad 119(107-128)$ \\
\hline & & $12.9(11.6-14.8) \quad 132(112-146)$ \\
\hline
\end{tabular}

Details are given in the text. Briefly, ants became habituated to cocaine, and dependent on its consumption. The effects of the alkaloid rapidly and sigmoidally decreased in the course of time, ending in about 4 - 5 hours; this observation is also presented in Figure 3 (empty squares).

\subsection{Concerning Atropine}

\subsubsection{Effect on Ants' Locomotion}

Atropine did not affect the ants' locomotion: the insects went on walking at the same linear speed $(14.5 \mathrm{~mm} / \mathrm{sec}$ vs $\left.14.0 \mathrm{~mm} / \mathrm{sec} ; \chi^{2}=2.78, \mathrm{df}=2, \mathrm{P}>0.20\right)$ with a nearly identical sinuosity (101 ang deg./cm $v s 114$ ang. deg. $/ \mathrm{cm} ; \chi^{2}=1.62, \mathrm{df}=2, \mathrm{P}>0.30$; Table 7 , line 1$)$.

\subsubsection{Effect on Ants' Precision When Reacting}

Under atropine consumption, ants seemed having difficulties in olfactorily perceiving the source of alarm pheromone. When they sufficiently perceived this source, they moved towards it, but often, they badly perceived it and did not well orient themselves towards it. Finally, their orientation had a median value of 55 ang. deg. while during the control experiment, this value equaled 33.8 ang. deg. $\left(\chi^{2}=9.56, \mathrm{df}=2, \mathrm{P}<0.01\right.$; Table 7 , line 2).

\subsubsection{Effect on Ants' Response to Their Pheromones}

Once more, under atropine consumption, the ants' olfactory perception seemed to be affected. The ants moved their antennae, cleaned them, moved slowly, stopped, and followed again the trail with difficulties. Their trail following behavior had a media value of 6 arcs, while the control value was $12.5 \operatorname{arcs}\left(\chi^{2}=8.38, \mathrm{df}=3,0.02<\mathrm{P}\right.$ $<0.05$; Table 7, line 3).

\subsubsection{Effect on Ants' Audacity}

After having consumed atropine for three days, no more or fewer ants came onto the presented tower (Table 7 , line $4 ; \mathrm{U}=137, \mathrm{Z}=1.69, \mathrm{P}=0.09)$. Thus, the ants' audacity was not affected by atropine consumption.

\subsubsection{Effect on Ants' Consumption of Food}

After having consumed atropine for four days, the ants statistically and obviously consumed less meat food. They were four times less numerous on the presented T. molitor larvae (Table 7, line 5; $\mathrm{U}=0, \mathrm{Z}=5.19, \mathrm{P}=$ $0.000)$. 
Table 7. Effect of atropine on seven physiological and ethological functions

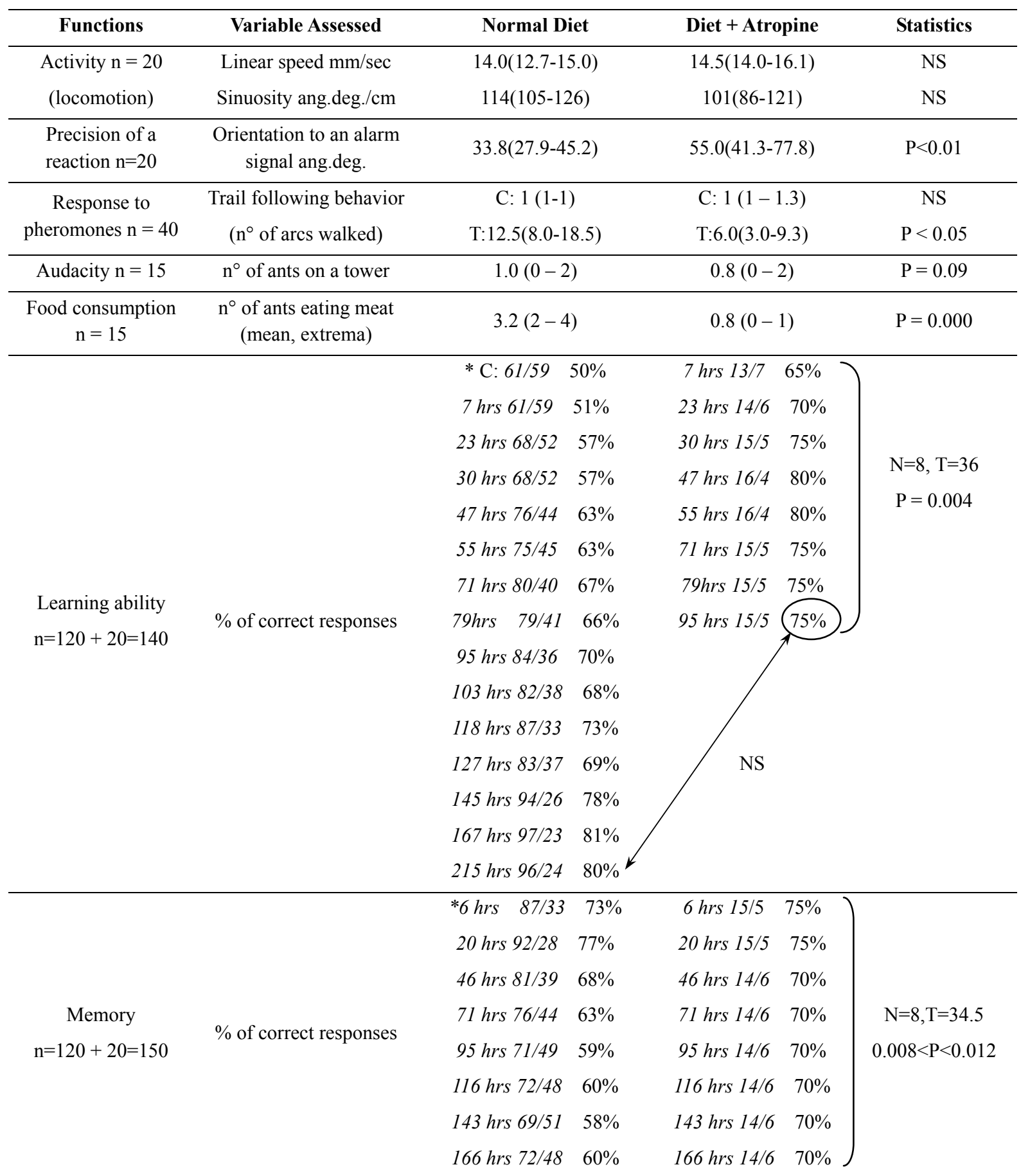

Details are given in the text. Briefly, atropine did not affect the ants' linear and angular speed nor their audacity; it affected the ants' olfactory perception and consequently decreased the precision of their response to the alarm pheromone as well as their response to the trail pheromone; it decreased their food consumption. Under this alkaloid consumption, ants soon acquired visual conditioning but did not reach a higher score, and better memorized the learned visual cue. The latter result is graphically presented in Figure 2 (empty triangles). $*=$ results obtained by Cammaerts et al. (2011).

\subsubsection{Effect on Ants' Conditioning Capability}

Ants having consumed atropine for seven days soon acquired operant visual conditioning: after 7, 23, 30, and 47 hrs of training, they reached the conditioning scores of $65 \%, 70 \%, 75 \%$, and $80 \%$ respectively, while under 
normal diet, their score then equaled $51 \%, 57 \%, 57 \%$, and $63 \%$ and reached $80 \%$ after $167 \mathrm{hrs}$ of training. This result was statistically significant $(\mathrm{N}=8, \mathrm{~T}=36, \mathrm{P}=0.004)$. After having reached $80 \%$ of conditioning in $47 \mathrm{hrs,}$ the ants having consumed atropine no longer increased their conditioning score and maintained themselves at the $75 \%-80 \%$ level (Table 7, line 6; Figure 2, left part, empty circles and triangles). They so more quickly acquired conditioning but did not reach a better score.

\subsubsection{Effect on Ants' Memory}

After that the green follow cube was removed from the ants' food site, the ants' conditioning score (under atropine consumption) first decreased from $75 \%$ to $70 \%$, like it decreased when ants received no atropine, then stayed at that rather high value for at least $200 \mathrm{hrs}$ (Table 7, line 7; $\mathrm{N}=8, \mathrm{~T}=34.5,0.008<\mathrm{P}<0.012$; Figure 2, right part, empty circles and triangles), the ants retaining so $20 \%$ of their learning instead of $10 \%$ when consuming no atropine. Thus, atropine somewhat increased the ants' long-lasting visual memory.

\subsubsection{Ants' Habituation to Atropine}

Under atropine consumption, the ants' locomotion was not affected (see above). Another parameter was thus used for examining the ants' habituation to atropine: the ants' orientation towards an isolated worker's head, a behavior affected by the alkaloid. After seven days of atropine consumption, the ants' orientation towards an alarm signal was still affected, even somewhat more than after one day of this alkaloid consumption (Table 8 , line $\left.1 ; \chi^{2}=12.38, \mathrm{df}=1, \mathrm{P}<0.001\right)$. Ants' olfactory perception went on being affected by atropine, and so ants did not become habituated to that alkaloid consumption.

\subsubsection{Ants' Dependence on Atropine}

After seven days of atropine consumption, ants were presented with sugar food free of atropine and sugar food containing this alkaloid. They came onto the food free of the alkaloid and drunk, or went to the food containing atropine, tasted it, then went away and moved towards the food free of the alkaloid. Meanly $8.3 \%$ ants drunk the food containing atropine, while 91.7 drunk the food free of that alkaloid (Table 8 , line $2 ; \chi^{2}=44.8, \mathrm{df}=1, \mathrm{P}<$ 0.001). Thus, ants did not become dependent on atropine consumption, and even avoided it.

Table 8. Habituation to atropine, dependence on its consumption, and duration of its effect on ants

\begin{tabular}{|c|c|c|}
\hline Effect Studied & Variable Assessed & Numerical Results \\
\hline $\begin{array}{l}\text { Habituation } \\
\text { (after } 7 \text { days) }\end{array}$ & $\begin{array}{l}\text { Orientation towards an alarm } \\
\text { signal ang.deg. }\end{array}$ & $\begin{array}{c}76.6(50.3-92.4) \quad v s \text { control: } \mathrm{p}<0.001 \\
v s \text { one day: NS }\end{array}$ \\
\hline $\begin{array}{l}\text { Dependence } \\
\text { (20 counts) }\end{array}$ & $\begin{array}{c}\text { choices of sugar water +atropine } \\
\text { vs sugar water }\end{array}$ & $\begin{array}{ll}\text { nest } 1: 2 \text { ants } v s & 18 \text { ants }=2 / 20=10 \% \\
\text { nest } 2: 3 \text { ants } v s & 45 \text { ants }=3 / 48=6.6 \%\end{array}$ \\
\hline Duration of effect & $\begin{array}{l}\text { Orientation towards an alarm } \\
\text { signal ang.deg. }\end{array}$ & $\begin{array}{cc}\text { T 0hrs } & 67.7(53.6-82.5) \\
T 1 h r s & 60.4(43.5-75.6) \\
T 21 / 2 h r s & 59.4(43.1-76.9) \\
T 41 / 2 h r s & 55.7(503-66.4) \\
T 71 / 2 h r s & 45.4(34.6-65.1) \\
T 10 h r s & 43.1(37.4-54.0) \\
T 24 h r s & 41.1(33.0-48.0)\end{array}$ \\
\hline
\end{tabular}

Details are given in the text. Briefly, ants did not become habituated to atropine, and did not become dependent on its consumption (they obviously preferred food free of atropine). The effects of this alkaloid first rapidly then slowly (so exponentially?) decreased in the course of time, ending in 20 - 30 hours; this observation is also presented in Figure 3 (empty triangles).

\subsubsection{Time Period during Which Consumed Atropine Affected the Ants}

Fourteen days after that the ants had consumed atropine, they no longer received this alkaloid for one day. Then, they once more received sugar water containing atropine and came drinking this liquid food. One hour later, at a given recorded time, this food was removed from the ants' tray and replaced by sugar water free of atropine. From that time, the ants' orientation towards an isolated worker's head was examined at successive given and 
recorded times (Table 8 , line 3; Figure 3, empty triangles). At $\mathrm{t}=4 \frac{1}{2} \mathrm{hrs}$, the ants' orientation was still statistically affected $\left(\chi^{2}=8.11, \mathrm{df}=1, \mathrm{P}<0.01\right)$; at $\mathrm{t}=10 \mathrm{hrs}$, the effect of atropine was only slightly perceptible and at the limit of statistical significance $\left(\chi^{2}=4.59, \mathrm{df}=2,0.05<\mathrm{P}<0.10\right)$. So, the effects of this alkaloid decreased rapidly during one or two hours, then went on vanishing slowly for $24-30 \mathrm{hrs}$.

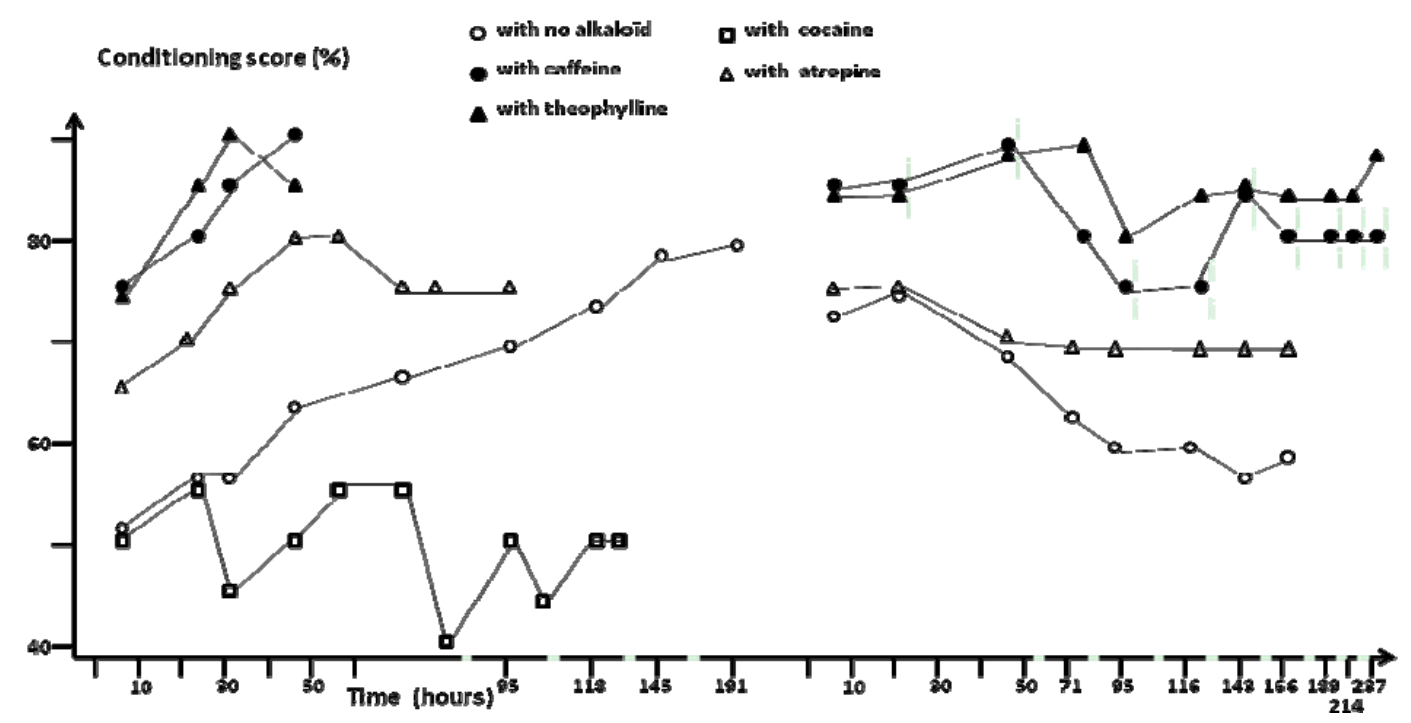

Figure 2. Kinetics of the acquisition (left graphs) and the loss (right graphs) of operant visual conditioning by ants consuming normal diet (empty circles), caffeine (black circles), theophylline (black triangles), cocaine

(empty squares) or atropine (empty triangles)

Obviously, the two first alkaloids increased the ants' ability in acquiring conditioning and improved their memory, theophylline being the most efficient as for these effects; cocaine had a negative effect on these abilities and atropine, a moderated positive effect.

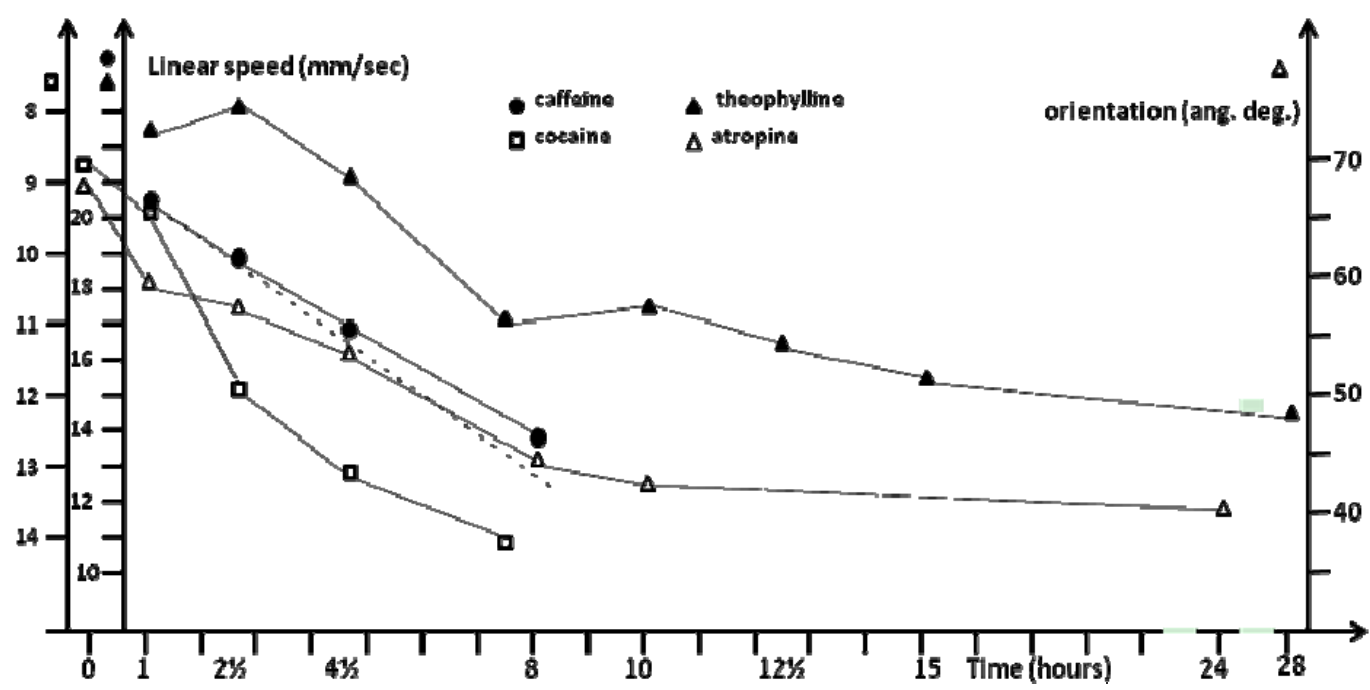

Figure 3. Loss of the effects induced by caffeine (black circles), theophylline (black triangles), and cocaine (empty squares) which Y axis is on the left (linear speed) as well as by atropine (empty triangles) which Y axis is on the right (orientation) after consumption of these substances ended

For caffeine, the loss was immediate and exponential; for theophylline, it was delayed and sigmoid; for cocaine, it was immediate, rapid and sigmoid; for atropine, it was first rapid then rather slow, so probably exponential 


\section{Discussion}

We examined the effects, on ants, of four commonly used alkaloids, caffeine, theophylline, cocaine and atropine (Figure 4). We found that caffeine and theophylline increase the ants' speed of locomotion, slightly decrease the precision of their response, do not affect their response to pheromones, nor their audacity, and slightly reduce their consumption of food. Each of these two alkaloids, especially theophylline, spectacularly increases the ants' ability in acquiring conditioning and memory. The ants do not develop habituation to or dependence on each of these two alkaloids. At the end of consuming each of these two alkaloids, their effects decrease in the course of time: the effects of caffeine exponentially vanish in $11-16$ hours; the effects of theophylline remain intact for 4 hours, and then sigmoidally vanish in about 28 hours. Cocaine decreases the ants' speed of locomotion, their precision of reaction, and their response to pheromone; it largely increases their audacity and reduces their consumption of food. Under cocaine consumption, ants retain nothing of a visual conditioning; they might still have a very short-lasting memory but no longer a long-lasting one. In a few days, the ants become habituated to the consumption of cocaine, and develop a strong dependence. The effects of cocaine vanish in 4 to 5 hours. Atropine does not affect the ants' locomotion but seems to reduce their olfactory perception and consequently decreases their orientation towards an alarm signal as well as their trail following behavior. This alkaloid does not affect the ants' audacity but decreases their food consumption. It increases the ants' rapidness in acquiring visual conditioning but not their conditioning score; it slightly increases the ants' visual long-lasting memory. Ants do not become habituated to nor dependent on, such alkaloid consumption.

All the effects revealed using ants as biological models are in agreement with those previously observed in mammals (Arnaud, 1987; Juliano \& Griffiths, 2004; Brady, Lydiard, Malcolm, \& Ballenger, 1991; Lupica \& Berman, 1988; Vaubourdolle, 2007 and references therein) and in bees (Chittka \& Peng, 2013). Indeed, these observations are, briefly, the following ones:

Caffeine is present in several plants such as coffee tree, tea plant, guarana, yerba mate, and cacaoyer; it is commonly consumed by human beings since it is present in coffee, tea, cacao, ice tea, and energizing drinks. It is rapidly and nearly completely assimilated by the organism, and quickly reaches the brain. Caffeine increases the individuals' awakening and decreases their physical and intellectual tiredness. This alkaloid increases the level of blood glucose, having a positive impact on the functioning of the brain as well as the muscles. Among others, nerve cells become more active and the cognitive performances of higher quality. As for the effect of this alkaloid on memory capacity, some kinds of memorization would be increased, but not all. Chittka and Peng (2013) showed that caffeine increases bees' memory. Caffeine is also known for having a tendency in reducing the individuals' appetite and for increasing their water elimination. Theophylline is present in several plants such as the tea plant, coffee tree, cacaoyer, guarana, yerba mate; it is commonly consumed by human beings via coffee, tea, cacao, and energizing drinks. This alkaloid increases the level of blood calcium, and consequently improves the functioning of the muscles. It increases the level of cyclic AMP, and consequently the quantity of available glucose, which induces a better general neuronal functioning. Theophylline increases the respiratory function, and is commonly used for helping people suffering from respiratory deficiencies. However, this last effect is still a matter of experimental investigation in order to confirm and elucidate the medical use of theophylline. Cocaine is a tropane alkaloid extracted from the plant 'coca'. It is known that persons consuming cocaine progressively become accustomed to and soon dependent on such consumption. These persons eat less, present unusual behavior, are no longer inhibited in performing risky tasks, and are less sensitive to pain. Atropine is a tropane alkaloid present in several Solanaceae plants such as belladonna, datura, jusquiame, and mandragore. Atropine sulfate is used in medicine for its negative effect on the cholinergic neurotransmissions, and consequently its positive effect on the adrenergic neurotransmissions. It can also be used as an antidote, but the quantity used must be limited for avoiding atropine poisoning. This alkaloid slows olfactory perception while diminished cholinergic neuronal activity does not. High amounts of atropine inhibit several physiological secretions, and increase the sense of pain.

In the present study, ants revealed several of the known effects of caffeine, theophylline, cocaine and atropine. These insects may thus be adequate biological models, at least initially, for studying effects of substances or treatments, before experimenting on mammals. The observations made on ants may be even more precise, more complete, and obtained in a shorter time period than those performed on mammals. For instance, the effect of theophylline on learning and memorization was not previously known as we could make using ants. Also, the decrease, in the course of time, of the alkaloid effects could be more precisely described when using ants. By doing so, it appeared that caffeine and theophylline are differently eliminated: the first alkaloid is immediately and exponentially eliminated while the second one is sigmoidally eliminated after some delay. Cocaine is rapidly and sigmoidally eliminated in a few hours, while atropine is first quickly, and then very slowly, eliminated. In 
the same way, ants, adequately tested, can objectively reveal the impact of substances (or treatments) on consumption of food, audacity, habituation and dependence.

Let us remark that cocaine decreased the ants' food consumption and this might have had a negative impact on the ants' conditioning ability, since food (meat food without cocaine) was used as a reward during training. But theophylline also slightly reduced the ants' food consumption though largely increasing the ants' ability in acquiring conditioning and improving their visual memory. Consequently, the adverse effect of cocaine on memorization must be seen as true, independent of the ants' lower consumption of food.

Concerning dependence, none was observed, in ants, for caffeine and theophylline. However, it is commonly accepted that people become dependent on these alkaloids. They are bitter and generally consumed at a concentration of about $1 / 1,000$, which cannot be perceived. People might become dependent on other substances contained in or linked to food containing these alkaloids. On the contrary, a strong dependence on cocaine consumption was observed in ants, what also occurs in human beings.

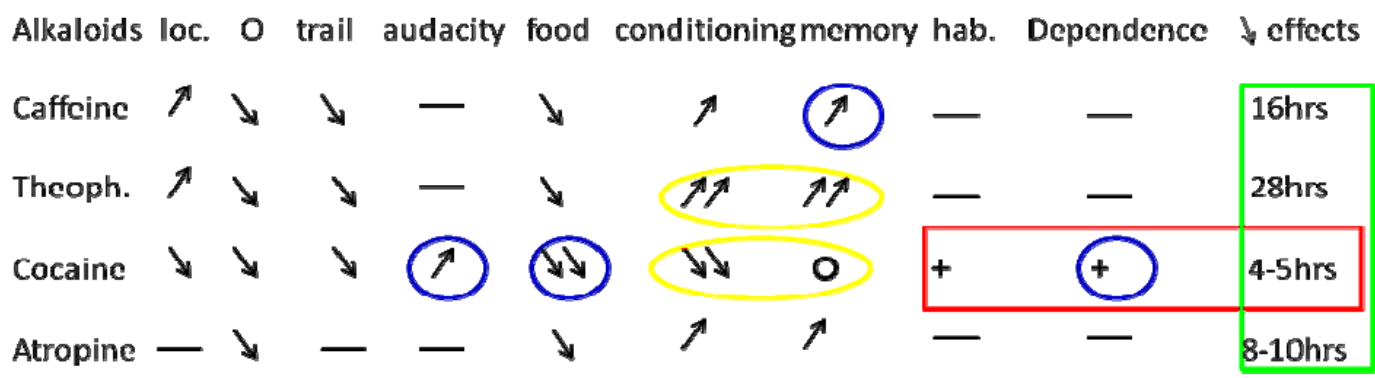

Figure 4. Effects of four alkaloids, on basis of studies made on ants

Theoph.: theophylline; loc.: locomotion; O: orientation ( $\rightarrow$ precision of responses); trail: trail following behavior ( $\rightarrow$ responses to pheromones); food: food consumption; hab.: habituation to the alkaloid; $\searrow$ effects: vanishing of the effects after the alkaloid consumption ended. The studies confirmed known effects (blue), lead to more precise information (green), bring new ones (orange), and reveal that dependence occurs when habituation exists and effects quickly vanished (red).

In ants, caffeine, theophylline and atropine did not lead to habituation, nor to dependence, while cocaine lead to such ethological effects. The effects of caffeine, theophylline and atropine slowly vanished in the course of time, whereas the effects of cocaine quickly vanished. It might be postulated that substances leading to dependence are those which primarily affect the nervous system, to which habituation soon occurs and the effects of which rapidly vanish in the course of time.

So, in summary, ants have been satisfactorily used as biological models. Such use of animals as biological models, for studying genetic, physiological, ethological, or embryological problems, is necessary and common in sciences and medicine. Invertebrates are actually more and more employed for unfolding such issues, and some of them are become famous (see references in the introduction section). We here demonstrate that ants could also be used in this manner; they are available during the entire year, they require small housing areas, their maintenance is easy and very cheap. As a conclusion of the present work, ants may be used, initially, to analyze the effects of substances and other influences on living organisms, before investigations are carried out on animals whose maintenance and manipulation is expensive and time consuming. One elegant feature of using ants as experimental animals is that these insects do not lend themselves to psychological explanatory models; they do react to the actual adverse or beneficial effects of a given treatment. They might also serve to reveal adverse effects of large amounts of substances consumed as well as to approximately determine their lethal dose. Finally, it shall be noted that ants are very sensitive to chemical compounds; thus, they may also be used for detecting the presence of presumed elements in collected samples, as already demonstrated by Cammaerts et al. (2012).

\section{Acknowledgments}

We are very grateful to Dr R. Cammaerts who helped us with the Mann-Whitney U test analyses, and was indulgent while we made the long-lasting experiments. We genuinely thank two anonymous referees whose comments allowed us improving our paper. We feel indebted to Associate Professor Olle Johansson, at the Karolinska Institute, Stockholm, Sweden, who patiently corrected the English of our paper. Our greatest thanks 
are for the Editor in chief and the Editorial Assistant for their attention and their excellent work.

\section{References}

Abramson, C. I., Wells, H., \& Janko, B. (2007). A social insect model for the study of ethanol induced behavior: the honey bee. In R. Yoshida (Ed.), Trends in Alcohol Abuse and Alcoholism Research (pp. 197-218). Nova Sciences Publishers, Inc.

Andre, R. G., Wirtz, R. A., \& Das, Y. T. (1989). Insect Models for Biomedical Research. In A. D. Woodhead (Ed.), Nonmammalian Animal Models for Biomedical Research (November 13, 2008). Boca Raton, FL: CRC Press.

Arnaud, A. M. (1987). The pharmacology of caffeine. Progress in Drug Research, 31, 273.

Bateson, G. (1979). Mind and Nature: A Necessary Unity (Advances in Systems Theory, Complexity, and the Human Sciences). Hampton Press. ISBN 1-57273-434-5.

Billen, J., \& Morgan, E. D. (1998) Pheromone communication in social insects - sources and secretions. In R. K. Vander Meer, M. D. Breed, K. E. Espelie, \& M. L. Winston (Eds.), Pheromone Communication in Social Insects : Ants, Wasps, Bees, and Termites (pp. 3-33). Boulder, Oxford: Westview Press.

Brady, K. T., Lydiard, R. B., Malcolm, R., \& Ballenger, J. C. (1991). Cocaine induced psychosis. Journal of Clinical Psychiatry, 52, 509-512.

Cammaerts, M.-C. (2012b). Olfactory and visual operant conditioning in the ant Myrmica rubra (Hymenoptera, Formicidae). Bulletin de la Société Royale Belge d'Entomologie, 148, 199-208.

Cammaerts, M.-C., \& Cammaerts, D. (2012). Know-how of three Myrmica species foragers. Symposium de la Société Royale Belge d'Entomologie (December 7, 2012).

Cammaerts, M.-C., \& Gosset, G. (2014). Impact of age, activity and diet on the conditioning performance in the ant Myrmica ruginodis used as a biological model. International Journal of Biology, 6(2), 10-20. http://dx.doi.org/10.5539/ijb.v6n2p10

Cammaerts, M.-C. (2004). Operant conditioning in the ant Myrmica sabuleti. Behavioral Processes, 67, 417-425. http://dx.doi.org/10.1016/j.beproc.2004.07.002

Cammaerts, M.-C. (2007). Colour vision in the ant Myrmica sabuleti MEINERT, 1861 (Hymenoptera: Formicidae). Myrmecological News, 10, 41-50.

Cammaerts, M.-C. (2008). Visual discrimination of cues differing as for their number of elements, their shape or their orientation, by the ant Myrmica sabuleti. Biologia, 63, 1169-1180. http://dx.doi.org/10.2478/s11756-008-0172-2

Cammaerts, M.-C. (2012a). Navigation system of the ant Myrmica rubra (Hymenoptera, Formicidae). Myrmecological News, 16, 111-121.

Cammaerts, M.-C. (2013a). Ants' learning of nest entrance characteristics (Hymenoptera, Formicidae). Bulletin of Entomological Research, 6.

Cammaerts, M.-C. (2013b). Learning of trail following behaviour by young Myrmica rubra workers (Hymenoptera, Formicidae). ISRN Entomology, Article ID: 792891, p. 6.

Cammaerts, M.-C. (2014). Performance of the species-typical alarm response in young workers of the ant Myrmica sabuleti is induced by interactions with mature workers. Journal of Insect Sciences (In press).

Cammaerts, M.-C. (2014). Learning of foraging area specific marking odor by ants (Hymenoptera, Formicidae). Journal of Entomological Research (In press).

Cammaerts, M.-C., \& Nemeghaire, S. (2012). Why do workers of Myrmica ruginodis (Hymenoptera, Formicidae) navigate by relying mainly on their vision? Bulletin de la Société Royale Belge d'Entomologie, 148, 42-52.

Cammaerts, M.-C., \& Rachidi, Z. (2009). Olfactive conditioning and use of visual and odorous elements for movement in the ant Myrmica sabuleti (Hymenoptera, Formicidae). Myrmecological News, 12, 117-127.

Cammaerts, M.-C., Morel, F., Martino, F., \& Warzée, N. (2012). An easy and cheap software-based method to assess two-dimensional trajectories parameters. Belgian Journal of Zoology, 142, 145-151.

Cammaerts, M.-C., Rachidi, Z., \& Cammaerts, D. (2011). Collective operant conditioning and circadian rhythms in the ant Myrmica sabuleti (Hymenoptera, Formicidae). Bulletin de la Société Royale Belge d'Entomologie, $147,142-154$.

Cammaerts, M.-C., Rachidi, Z., Bellens, F., \& De Doncker, P. (2013). Food collection and responses to 
pheromones in an ant species exposed to electromagnetic radiation. Electromagnetic Biology and Medicine, 32(3), 315-332. http://dx.doi.org/10.3109/15368378.2012.712877

Cammaerts-Tricot, M.-C. (1973). Phéromone agrégeant les ouvrières de Myrmica rubra. Journal of Insect Physiology, 19, 1299-1315. http://dx.doi.org/10.1016/0022-1910(73)90213-8

Chittka, L., \& Peng, F. (2013). Caffeine boosts bees' memories. Science, $339,8$. http://dx.doi.org/10.1126/science.1234411

Deutsch, J. (1994). La drosophile: des chromosomes aux molécules (p. 112). In J. Libbey (Ed.). Paris.

Devineni, A. V., \& Heberlein, U. (2013). The evolution of Drosophila melanogaster as a model for alcohol addiction. Annual Review of Neurosciences, $121-138$. http://dx.doi.org/10.1146/annurev-neuro-062012-170256

Døring, T. D., \& Chittka, L. (2011). How human are insects and does in matter? Formosan Entomologist, 31, 85-99.

Hölldobler, B., \& Wilson, E. O. (1990). The ants (p. 732). Harvard University Press: Springer-Verlag Berlin. http://dx.doi.org/10.1007/978-3-662-10306-7

Juliano, L. M., \& Griffiths, R. R. (2004). A critical review of caffeine withdrawal: empirical validation of symptoms and signs, incidence, severity, and associated features. Psychopharmacology, 176, 1-29. http://dx.doi.org/10.1007/s00213-004-2000-x

Keller, L., \& Gordon, E. (2006). La vie des fourmis (p. 204). Odile Jacob, Paris.

Keller, R. A. (2011a). A phylogenetic analysis of ant morphology (Hymenoptera: Formicidae) with special reference to the Poneromorph subfamilies. Bulletin of the American Museum of Natural History, 355, 99. http://dx.doi.org/10.1206/355.1

Keller, R. A. (2011b). Ants protect their mouthparts by locking them in place. Colloque organized at Banyuls/mer (April, 2011).

Kolb, B., \& Whishaw, I. Q. (2002). Neuroscience \& cognition: cerveau et comportement (p. 635). New York, Basing Stoke: Worth Publishers.

Lupica, C. R., \& Berman, R. F. (1988). Atropine slows olfactory bulb kindling while diminished cholinergic innervation does not. Brain Research Bulletin, 203-209. http://dx.doi.org/10.1016/0361-9230(88)90180-3

Passera, L. (2006). La véritable histoire des fourmis (p. 340). Librairie Fayard.

Passera, L., \& Aron, S. (2005). Les fourmis: comportement, organisation sociale et evolution (p. 480). Ottawa, Canada: Les Presses Scientifiques du CNRC.

Siegel, S., \& Castellan, N. J. (1989). Nonparametric statistics for the behavioural sciences (p. 396). Singapore: McGraw-Hill Book Company.

Søvik, E., \& Barron, A. B. (2013). Invertebrate models in addiction research. Brain Behavior and Evolution, 82, 153-165. http://dx.doi.org/10.1159/000355506

Vaubourdolle, M. (2007). Médicaments (Tome 2, Ed. 3, p. 867). France: Editeurs Wolters Kluwer.

Wehner, R., \& Gehring, W. (1999). Biologie et physiologie animals (p. 844). De Boek Université, Thieme Berlag, Paris, Bruxelles.

Wolf, F. W., \& Heberlein, U. (2003). Invertebrate models of drug abuse. Journal of Neurobiology, 54, $161-178$. http://dx.doi.org/10.1002/neu.10166

\section{Copyrights}

Copyright for this article is retained by the author(s), with first publication rights granted to the journal.

This is an open-access article distributed under the terms and conditions of the Creative Commons Attribution license (http://creativecommons.org/licenses/by/3.0/). 